Portland State University

PDXScholar

1978

\title{
Empathetic reactions derived through abstract sculptured forms
}

Bruce Frederick Literal

Portland State University

Follow this and additional works at: https://pdxscholar.library.pdx.edu/open_access_etds

Part of the Sculpture Commons

Let us know how access to this document benefits you.

Recommended Citation

Literal, Bruce Frederick, "Empathetic reactions derived through abstract sculptured forms" (1978).

Dissertations and Theses. Paper 2847.

https://doi.org/10.15760/etd.2841

This Thesis is brought to you for free and open access. It has been accepted for inclusion in Dissertations and Theses by an authorized administrator of PDXScholar. Please contact us if we can make this document more accessible: pdxscholar@pdx.edu. 
AN ABSTRACT OF THE THESIS OF Bruce Frederick Literal for the Masters of Fine Arts in Art presented

T1tle: Empathet1c Reactions Der1ved Through Abstract Sculptured Forms APPROVED BY MEMBERS OF THE THESIS COMMITEEE. 7

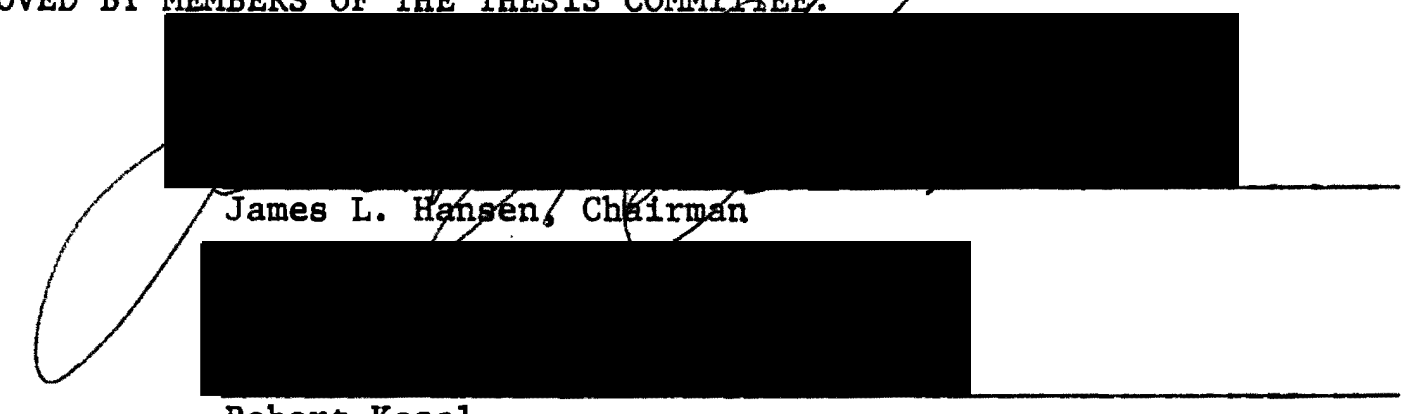

Robert Kasal

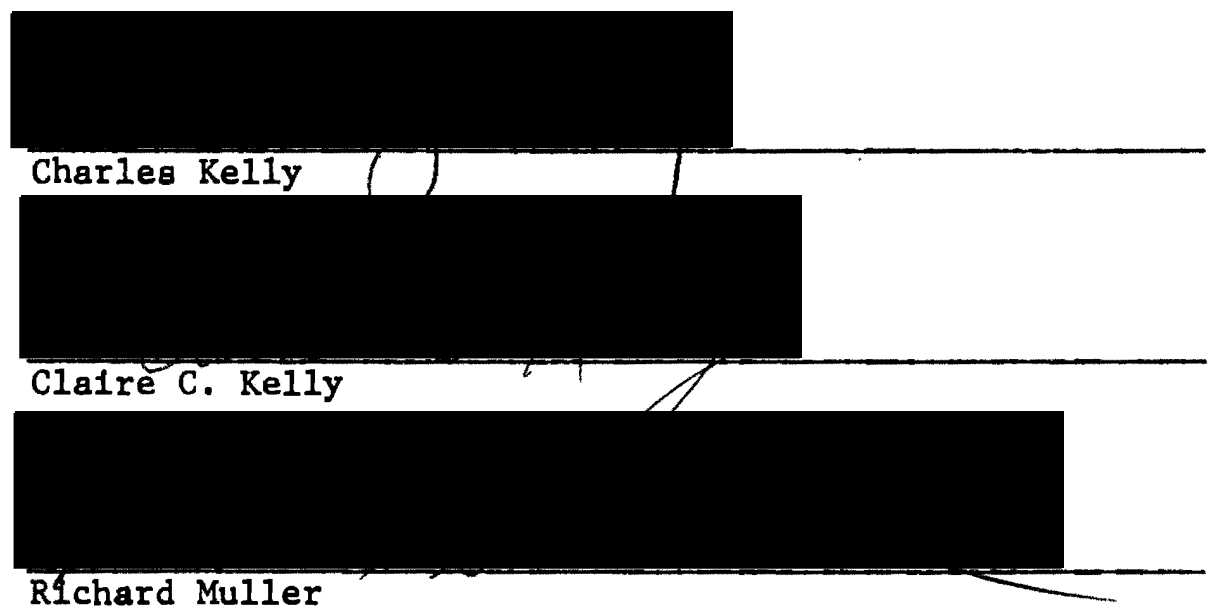

Th1s thesis project consists of sixteen abstract sculptures. The material most often used 18 polyester resin. The work explores the emotive potential of the relationship between the organic forms and the geometric spaces. The forms are derlved from observing the environment, other current artist's works, and the works of art history.

The sculptures generally divide into three groups. The first is 
composed of geometric and organic forms that are altered slightly so that aspects of each form reside in 1ts opposite. The second group maintains a purity of organic and geometric elements. Here a balance 1s kept by weighing the visual strength of each form. The third is like the second except that the organic forms are easily recognized as human forms.

Color is used to alter the Impact of a form. The whole body of work strlves for an equilibrium between form and color. 
TO THE OFFICE OF GRADUATE STUDIES AND RESEARCH:

The Members of the Committee approve the thesis of Bruce F. Literal presented June 9, 1978

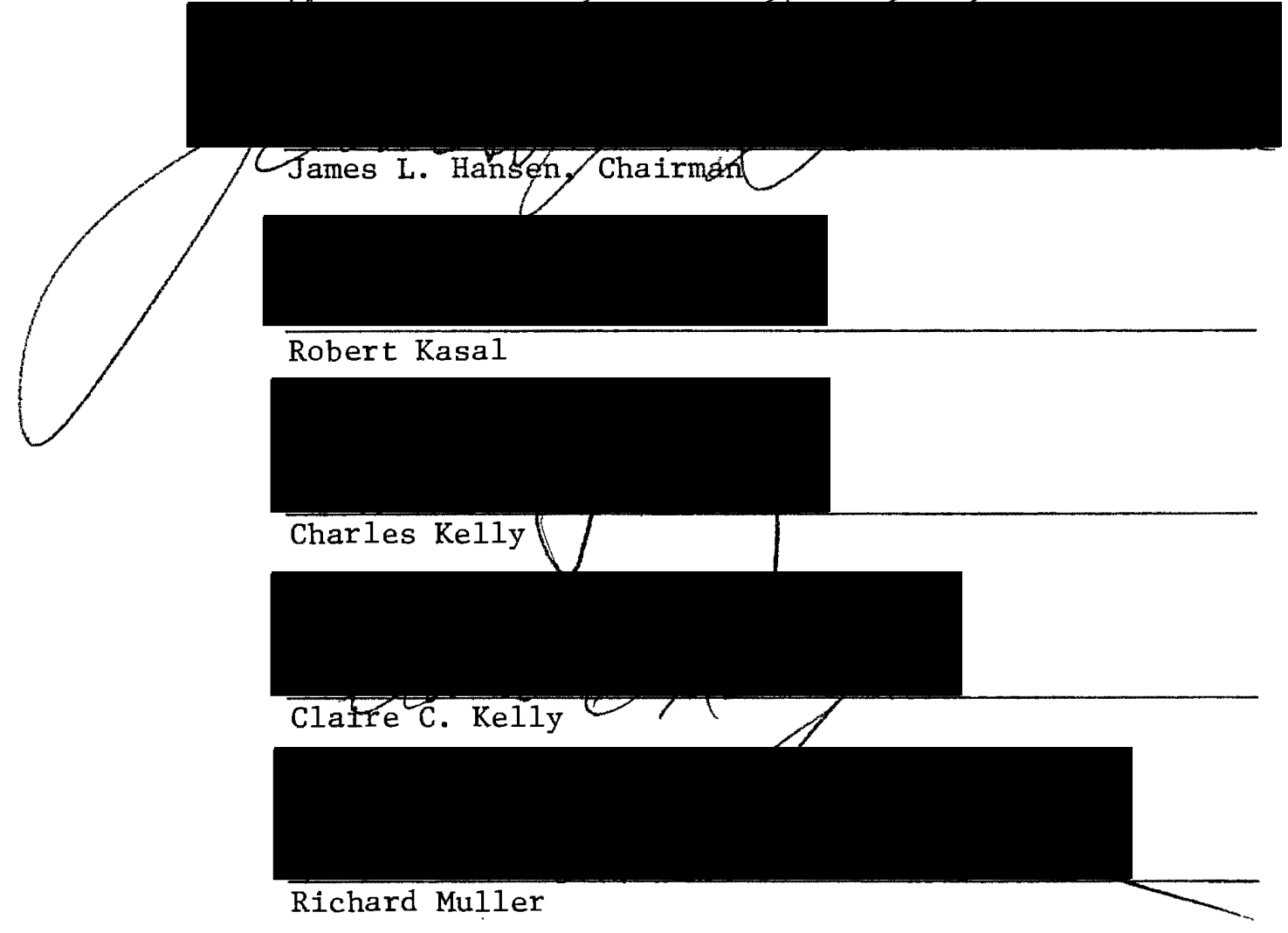

APPROVED:

Leonard B. Kimbrell, Head, Department of Art and Architecture

ᄃApproval not required

Stanley Rauch, Dean of Graduate Studies and Research 
EMPATHETIC REACTIONS DERIVED THROUGH

ABSTRACT SCULPTURED FORMS

by

BRUCE FREDERICK LITERAL

A thesis submitted in partial fulfillment of the requirements for the degree of

\author{
MASTER OF FINE ARTS \\ in \\ ART
}

Portland State University

1978 
TABLE OF CONTENTS

PAGE

LIST OF FIGURES . . . . . . . . . . . . . . . . v1

CHAPTER

I INTRODUCTION ......................... 1

Purpose ................. 1

Drawing .................. 1

Use of Color ............... . . 1

Medium .............. . 2

Bases ................ 2

II INFLUENCES . . . . . . . . . . . . 7

Cultural ................ 7

Contemporary .............. . 7

Individuals .............. 7

III THREE TYPES OF RESULTING SCULPTURE . . . . . . . . 12

IV DESCRIPTION OF INDIVIDUAL PIECES . . . . . . . . 14

Ananta . . . . . . . . . . . 14

Reclining Figure ............. 16

Ritual Hatchet . . . . . . . . . . 18

Ritual Disc ............. 20

Reclining Disc............. . 22

Monolith 73 . . . . . . . . . . 24

Tr1-øphere . . . . . . . . . . . 27 
Blue Sphere.... . . . . . . . . . . 28 Mother Nature's Silver Seed . . . . . . . 30 Dimension Disc ................. 33 Harlequin .................. 35 Smashed Hand Piece ............. . . 43 Peer-A-Mid . . . . . . . . . . . . . 4 46 Opposing Pyramid . . . . . . . . . . . . . 48 Face Cubes ................ 50 Body Cubes . . . . . . . . . . . . 52

V ILLUSTRATION CREDITS . . . . . . . . . . . . . . 55 
LIST OF FIGURES

F IGURE

PAGE

1 Egyptian Architecture . . . . . . . . . . . . . . 3

2 East Indian Sculpture . . . . . . . . . . . . 3

3 Chinese. Jade Carving . . . . . . . . . . . . . 3

4 N.W. Indian. Polychromed Rattle . . . . . . . . . 4

5 Antoine Pevsner. Sculpture . . . . . . . . . . . . 5

6 Claes Oldenburg. Sculpture . . . . . . . . . . 5

7 Frank Gallo. Sculpture . . . . . . . . . . . 6

8 Herd X. By Fritz Koenig . . . . . . . . . . . . 9

9 Henry Moore. Tunnel Drawing . . . . . . . . . . . 9

10 Jean Arp. Human Concretion . . . . . . . . . . . . 10

11 Isamo Noguchi. Black Sun . . . . . . . . . . . 10

12 Alberto Glacomett1. Man Pointing . . . . . . . . . . 11

13 Auguste Rodin. Iris, Messenger of the Gods . . . . . . 11

14 Ananta . . . . . . . . . . . . . . . 15

15 Ananta .................. . 15

16 Reclining Figure . . . . . . . . . . . . . 17

17 Reclining Figure . . . . . . . . . . . . . 17

18 Ritual Hatchet . . . . . . . . . . . . . 19

19 Ritual Hatchet . . . . . . . . . . . . . 19

20 Ritual Disc . . . . . . . . . . . . . . . 21

21 Ritual Disc,. . . . . . . . . . . . . . 21

22 Ritual Disc . . . . . . . . . . . . . . 21 
23 Reclining Disc . . . . . . . . . . . . . . 23

24 Reclining DIsc . . . . . . . . . . . . . 23

25 Reclining Disc . . . . . . . . . . . . . . 23

26 Monolith 73 . . . . . . . . . . . . . . 26

27 Monolith 73 . . . . . . . . . . . . . 26

28 Tr1-sphere . . . . . . . . . . . . . . . 29

29 Blue Sphere . . . . . . . . . . . . . . . 29

30 Mother Nature's Silver Seed . . . . . . . . . 32

31 Dimension Disc . . . . . . . . . . . . . 34

32 Dimension Disc . . . . . . . . . . . . . . 34

33 Harlequin . . . . . . . . . . . . . . 36

34 Harlequin . . . . . . . . . . . . . . 36

35 Drawing (1) $9 / 23 / 72$. . . . . . . . . . . . 37

36 Drawing (2) 9/23/72 ................ 37

37 Drawing (3) $9 / 24 / 72$. . . . . . . . . . . . 37

38 Drawing (4) $9 / 26 / 72$. . . . . . . . . . . . 38

39 Drawing (5) $9 / 29 / 72$. . . . . . . . . . . . 38

40 Drawing (6) $9 / 29 / 72$. . . . . . . . . . . . . 39

41 Drawing (7) $9 / 29 / 72$. . . . . . . . . . . . 39

42 Drawing (8) $9 / 29 / 72$. . . . . . . . . . . . . 40

43 Drawing (9), 10/7/72 ................ 40

44 Drawing (10) $10 / 28 / 72$. . . . . . . . . . . . 41

45 Drawing (11) $11 / 3 / 72$. . . . . . . . . . . . 41

46 Drawing (12) $11 / 22 / 72$. . . . . . . . . . . . . . 41

47 Drawing (13) $11 / 23 / 72$. . . . . . . . . . . . . . 41 
48 Drawlng (14) $11 / 24 / 72$. . . . . . . . . . . . 42

49 Drawing (15) $12 / 6 / 72$. . . . . . . . . . . . 42

50 Smashed Hand Piece . . . . . . . . . . . . . 45

51 Smashed Hand Plece . . . . . . . . . . . . . 45

52 Peer-A-Mid . . . . . . . . . . . . . 47

53 Peer-A-M1d . . . . . . . . . . . . . 47

54 Opposing Pyramid . . . . . . . . . . . . . . 49

55 Opposing Pyramid . . . . . . . . . . . . . . 49

56 Face Cubes . . . . . . . . . . . . . . . 51

57 Face Cubes . . . . . . . . . . . . . . . 51

58 Body Cubes . . . . . . . . . . . . . . . . 54

59 Body Cubes . . . . . . . . . . . . . . . . 54 
CHAPTER I

My purpose has been to explore the combination of intellectual and emotional elements in my sculpture. My work explores the emotive potential of the relationship between organic forms and geometric spaces. I have used abstract forms to demonstrate the various relationship of Iffe to a created environment (1.e., bulldings, walls, stairways, domes, doors, etc.). I hope that the completed work has incorporated in it the monumental, eternal quality of early Egyptian sculpture (F1g. 1) along with the grace and the dignity of that of the Gupta period In India $(\mathrm{F} \perp \mathrm{g}, 2)$.

I made drawings in a series, dated and numbered for reference purposes, so that I could develop many form variations in a short time perlod. These drawling progresstons could be used for later analysis (1.e. personal style of form development, other potential form 1deas, varlous color combinations, etc.). A series of drawings was made for each sculpture. To limit space I am using the series from only one plece, Harlequin (Figures 35 through 49).

I have experimented with color to heighten the mood of some pleces of sculpture. For centurles, palnters have used color to describe and intensify emotion and form. It seems reasonable that sculptors can also use color to helghten the viewer's emotional response. I do not mean that color should take the place of form, but rather that it should be derived from the basic nature of the form 1tself. I am Interested in the fact that sculptors have always, to some degree, used 
color (e.g., steel and bronze with warm or cool surface treatments, brightly painted geometric forms, the polychromed surfaces of Egyptian and Northwest Indian work (F1g. 4), and the glazed and lacquered surfaces of Chinese ceramic (Fig. 3) and wood sculpture), and I tried to expand on these 1deas in my own work.

My principal medium is resin, a relatively new medium in art. It has been pioneered by Individuals who, because of the newness of the material, are more techniclans than artists. Consequently, the products of their effort have remained in the realm of the decorative or craft arts. However, the sound rendering of forms in resin or plastic has been accomplished by a few artists such as Frank Gallo (F1g. 7), Antione Pevsner (FIg. 5), and Claes Oldenburg (Fig. 6). Resin as a sculpture medium, for my purposes, is more versatile than elther bronze or steel. Resin can be warm and soft in organic form, or it can be rigid and stone-1ike in geometric form. It also lends itself easily to a wide color range.

Several of my aculptures have traditional geometric bases, followIng the premise that a symmetrical form is more easily 1gnored and does not Interfere with looking at the sculpture. Another solution to the problem of bases is to create a sculpture whose base is an integral part of the sculpture. "Monolith" exemplifies this solution. 


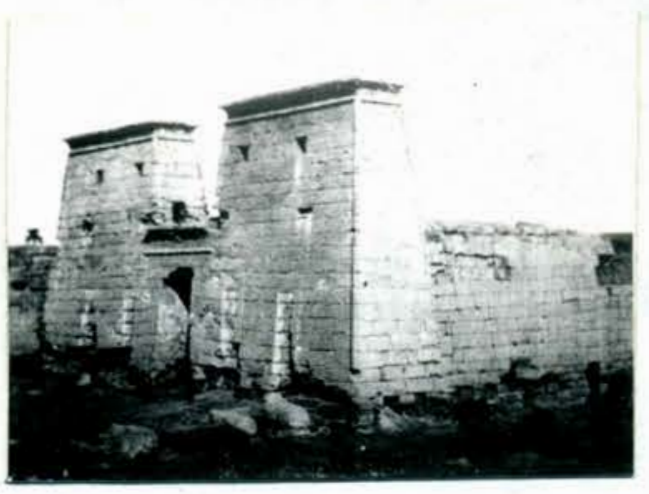

Figure 1. Egyptian Architecture. Karnak. Temple of Khons.

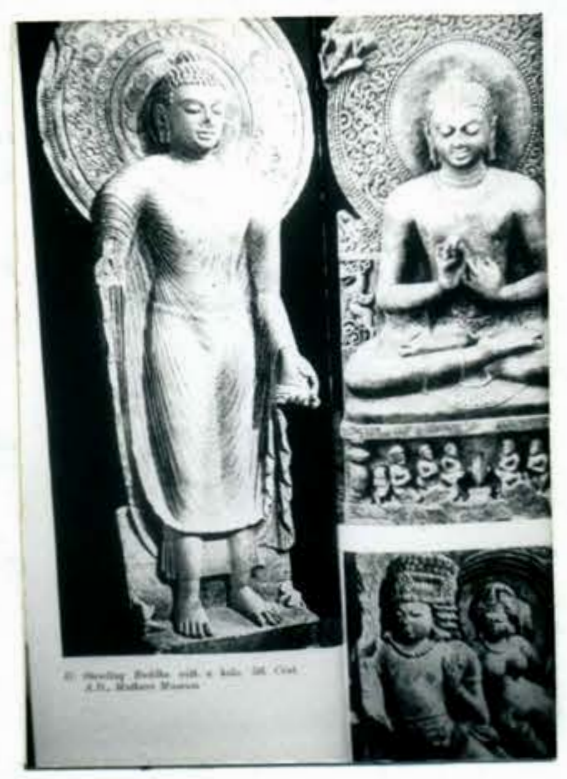

Figure 2. Gupta Period. East Indian sculpture.

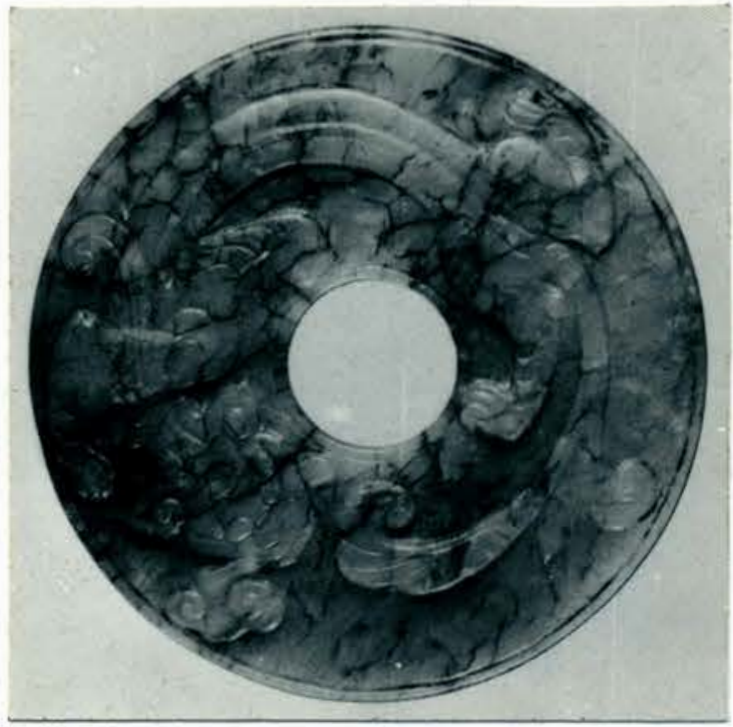

Figure 3. Chinese. P1 disc. Jade Carving. 


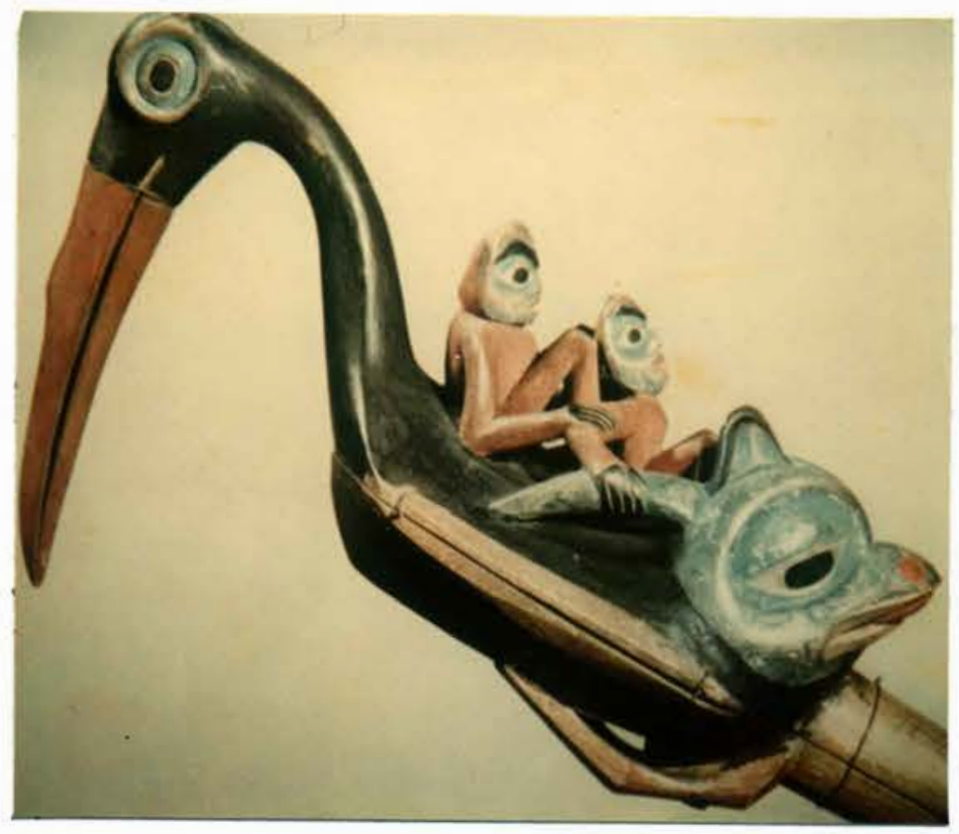

Figure 4. N.W. Indian. Polychromed Rattle. 


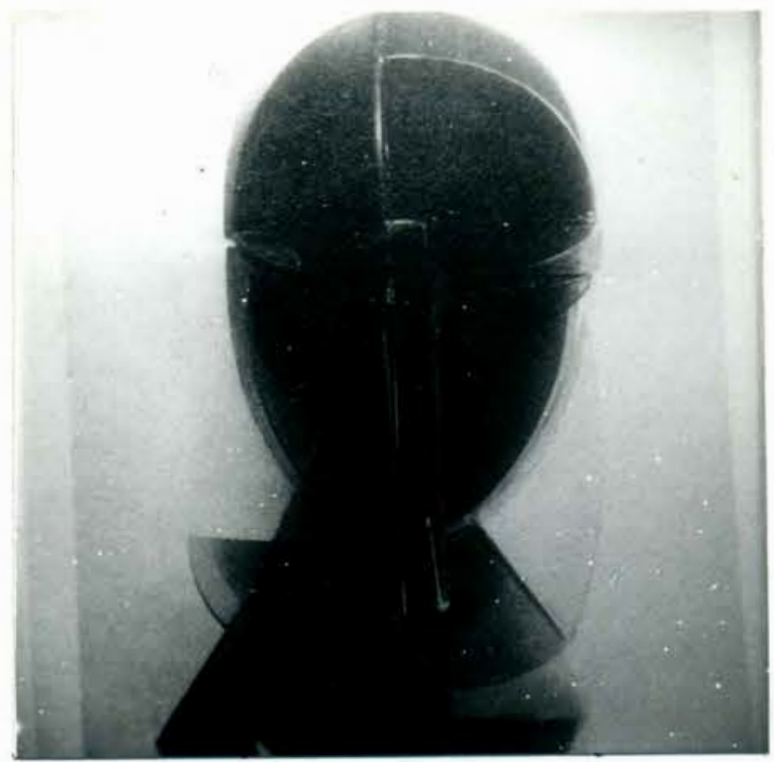

Figure 5. Antoine Pevsner. Sculpture.

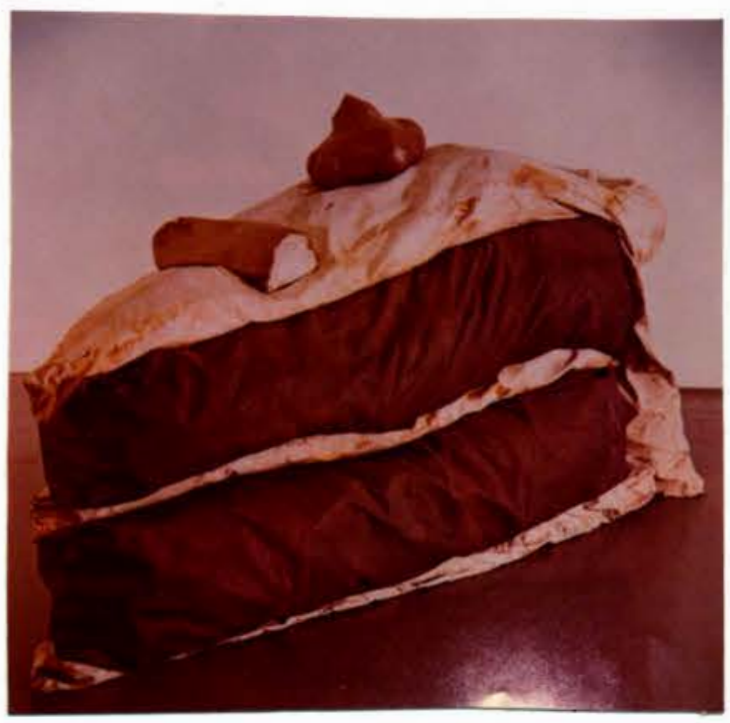

F1gure 6. Claes 01denburg. Sculpture. 


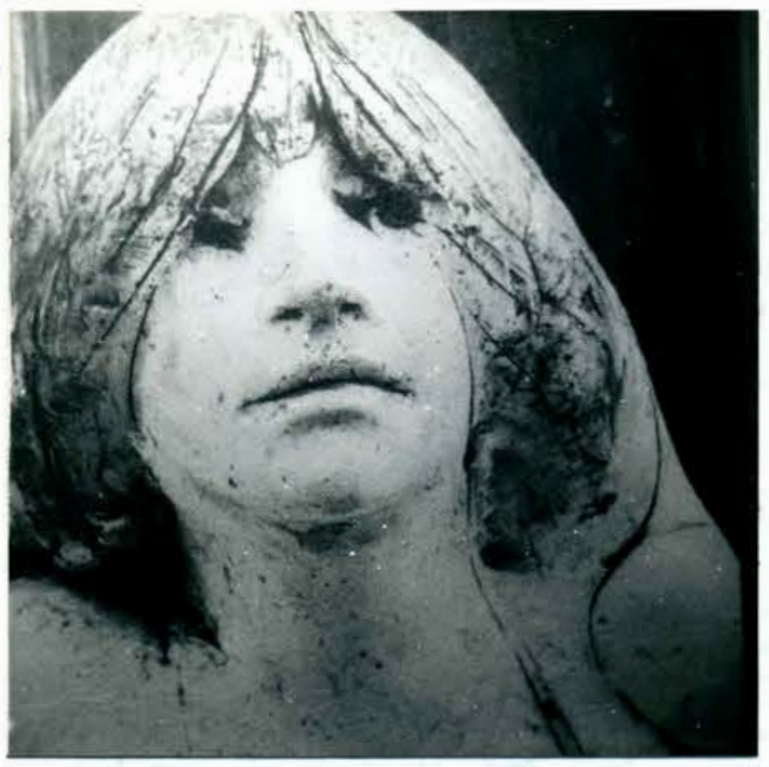

Figure 7. Frank Gallo. Sculpture. 
I can trace a number of cultural influences in my work. One of my earliest interests was the anclent Egyptlans whose monumental sculptures and architecture have a lasting quality that seems almost eternal. In my search for strong monumental forms I spend a great deal of time lookIng at art in a historical sense. I pick and choose those aspects that appear to have enduring presence and that seem to be mirrored in similar aspects in the present.

Though my strongest cultural influence is historical, I am also Influenced by my own culture, by current movements and styles. I find inspiration for my work by observing aspects of my own environment. When I decided to explore the relationship of architectural forms to organic shapes, the obvious starting point was my own interaction with architectural spaces and the feelings which the interaction inspired in me. From there I observed larger and larger groups of people. In the back of my mind was Fritz Koenig's "Herd X" (FIg. 8) which shows organic beings (steers) changing form and identity with increased numbers -the abstraction of an entity by increasing its numbers. When a steer becomes a herd or a person becomes a crowd, a concrete entity is transformed into an abstraction.

In addition to cultural influences, I can also see the influences of a number of individual sculptors on my work. The most important are: Henry Moore: In addition to the composition within the forms, I was also interested in the combination of forms he used. I was intrigued 
by his use of small, semi-abstract figures placed in architectural surroundings $(\mathrm{F} 1 \mathrm{~g}, 9)$.

Isamo Noguch1: I was most interested in his stone carving, especlally the "Black Sun" (FIg. 11) which I have seen many times in Seattle. Once again the aspect that interested me was the combination of geometric and organic elements.

Jean Arp: I see Arp's forms as a search for purtty of form which Moore and Noguchi approach but never quite achieve. His combinations of organic forms (FIg. 10) are most Impressive.

Alberto Giacomett1: He uses strong negative space to influence his flgures (Fig. 12). Form 1s compressed by space.

Auguste Rodin: I am Intrigued by Rodin's use of form (F1g. 13) to create areas of light: which flicker across the surface of the sculptures and give his forms a sense of life energy. 


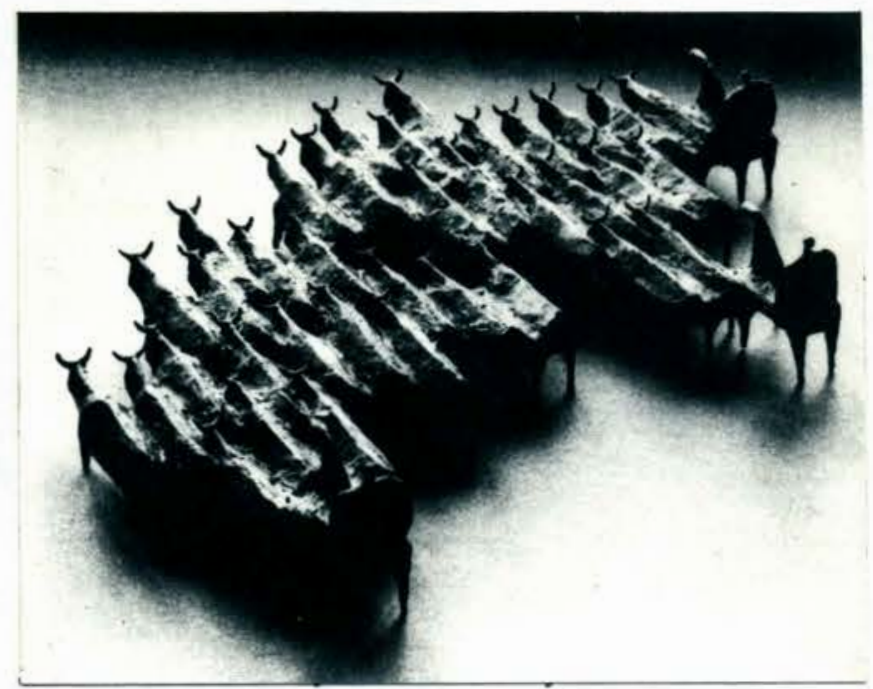

Figure 8. Herd X. By Fritz Koenig.

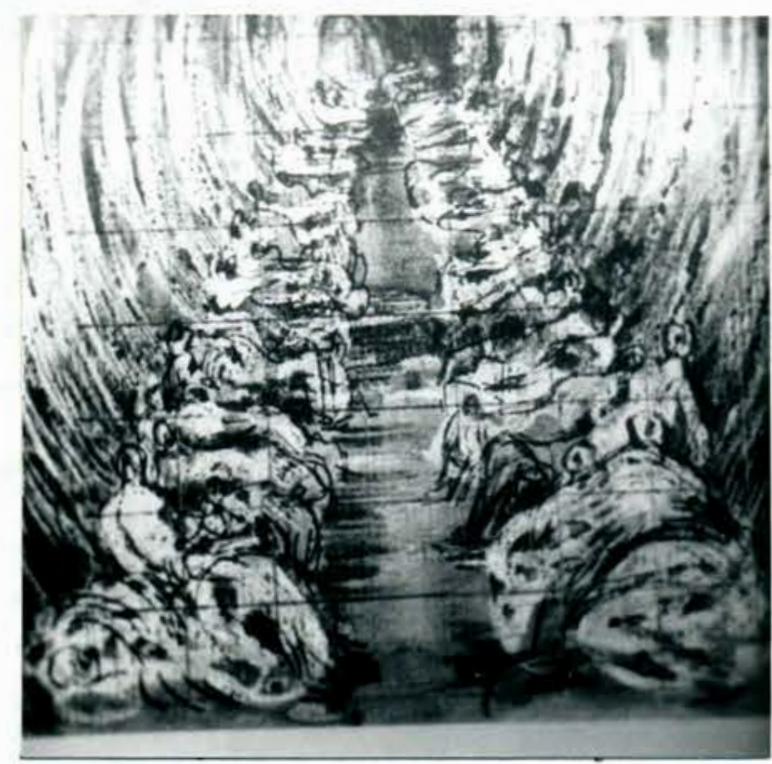

Figure 9. Tunne1 Drawing. By Henry Moore. 


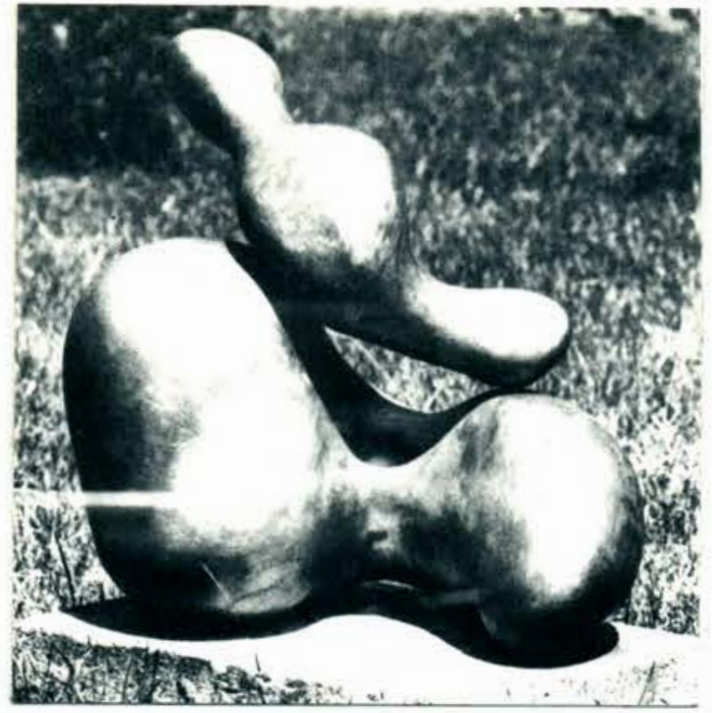

Figure 10. Human Concretion. By Jean Arp.

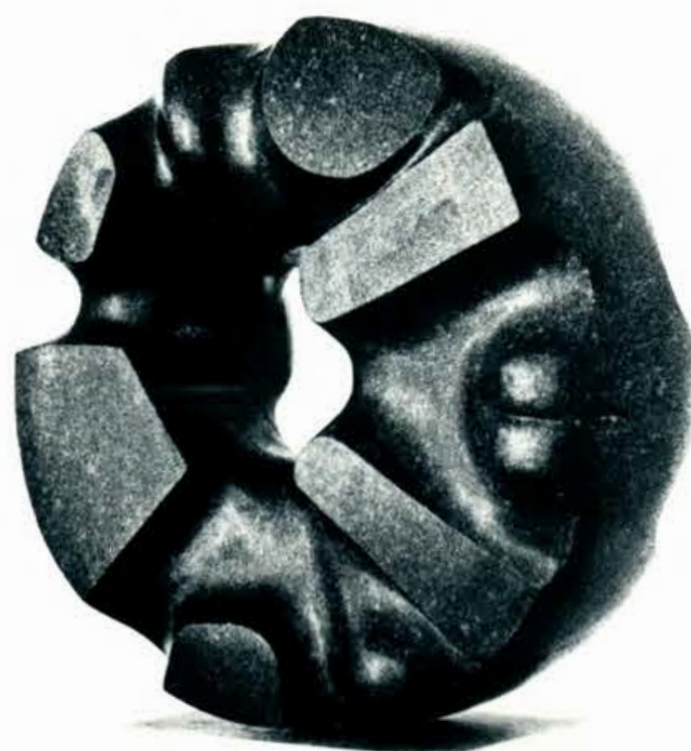

Figure 11. Black Sun. By Isamo Noguchi. 


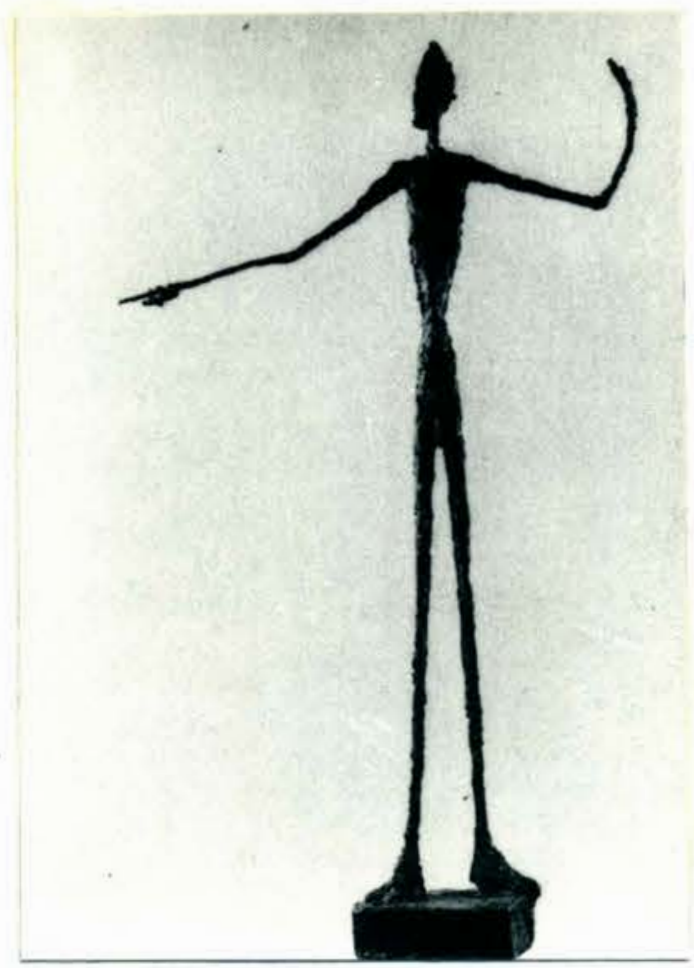

Figure 12. Man Pointing. By Alberto Glacometti.

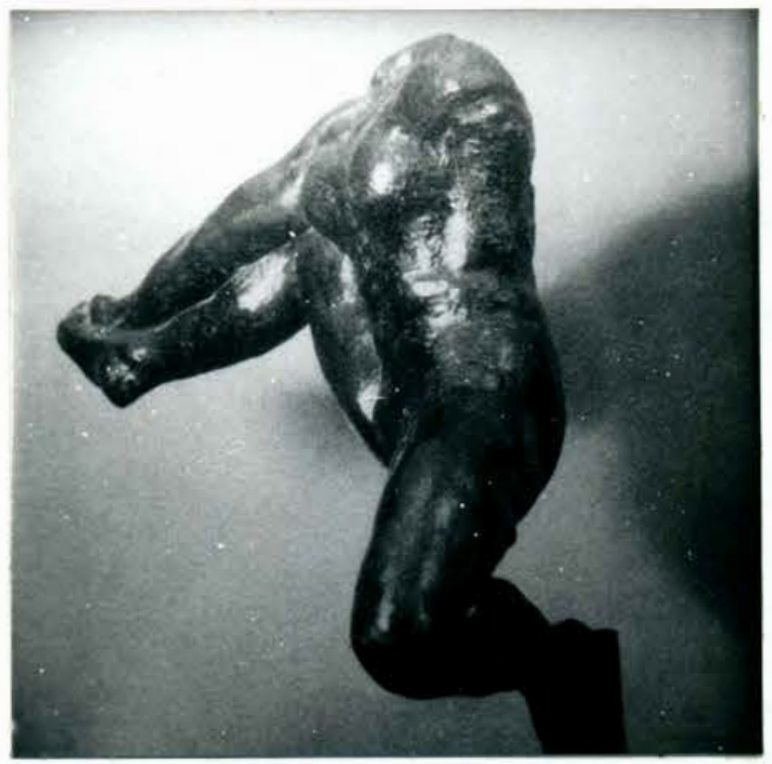

Figure 13. Iris, Messenger of the Gods. By August Rodin. 
CHAPTER III

Three types of sculptures have resulted from my otudy of the interrelation of organic (biomorphic) forms and geometric (architectonfc) spaces. All three afm at a balance with organic and geometric elements In equilibrium.

The first group Includes "Ananta" (F1g. 14-15), "Ritual Hatchet" (F1g. 18-19), "Ritual Disc" (Fig. 20-21-22), and "Reclining Figure" (F1g. 16-17). A balance has been achieved in this group by slightly altering a geometric form and an organic form so that they equally resemble each other. Portions of the geometric forms take on curved lines which suggest the organfc shapes. Conversely, the organfc forms take on some hard-edged lines which suggest the geometric forms. I equate this type of form development to a man wearing a finely tailored sult. The organic form takes on geometric elements.

The second group includes "Tr1-Sphere" (F1g. 28), "Blue Sphere" (FIg. 29), "Mother Nature's Silver Seed" (FIg. 30), and "Dimension Disc" (F1g. 31-32). In this group I have attempted to balance forms embodylng directly opposing natures. Geometric or architectural forms are inherently cold, hard, inert, and flat. Organic or blomorphic forms are composed of warm, soft, active, and curved elements. Usually the arch1tectural form is larger. The two differing forms remain pure and true to their natures while a visual equilibrium is found by balancing the strengths of each.

The third group includes "Smashed Hand P1ece" (F1g. 50-51), 
"Peer-a-mid" (Fig. 52-53), "Pyramid Opposing" (Fig. 54-55), "Face Cubes" (F1g. 56-57), and "Body Cubes" (F1g. 58-59). This group 1s a variation on the balance established in the second group. The difference is not in the geometric forms. The abstract organic forms are replaced by human figurative elements. The problem of balancing elements is compounded by the direct and strong associations inspired by the human organic forms. Therefore, more emphasis is placed on the geometric forms. This is a most difficult balance to attain. Due to variations in the viewer's feelings, the balance is never consistent. 
CHAPTER IV

\author{
ANANTA \\ East Indian Serpent - headed Goddess (Fig. 14-15)
}

\title{
Composition
}

The form is basically organic in nature, yet all lines that occur in the sculpture are geometric. The composition is a balance between organic form and geometric line. Because of its size, this piece will probably be displayed surrounded by architecture. Vertical and horizontal geometric lines in the plece will integrate it with the architectonic surroundings. The color is black with a tint of green. The form reminded me of a monitor lizard, and this association accounts for the addition of the greenish tone to the plece.

\section{Material}

Greenish-black cast resin.

\section{Critique}

Ananta is a single entity like the bust of a person. The association will be stronger, against architectural surroundings. The intention described in the Composition section (above) is generally realized.. Its vertical and horizontal lines will integrate it with architectural surroundings. 


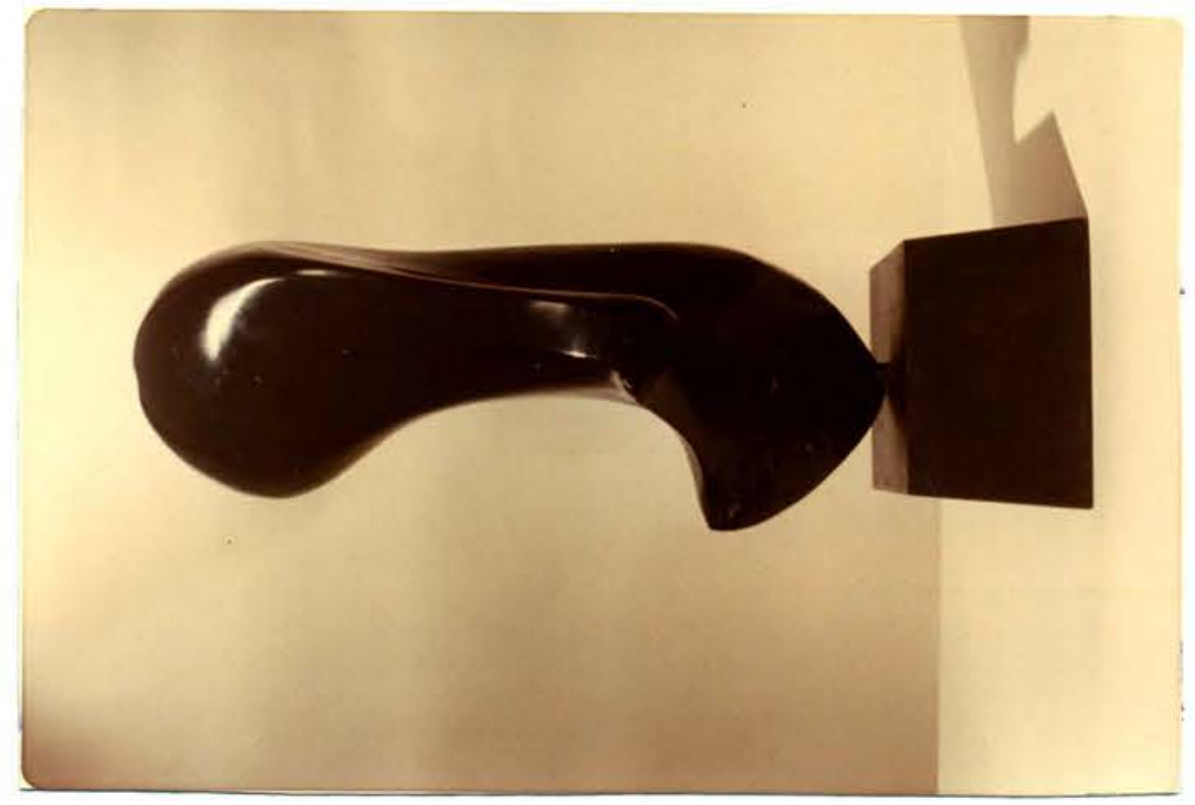



年|

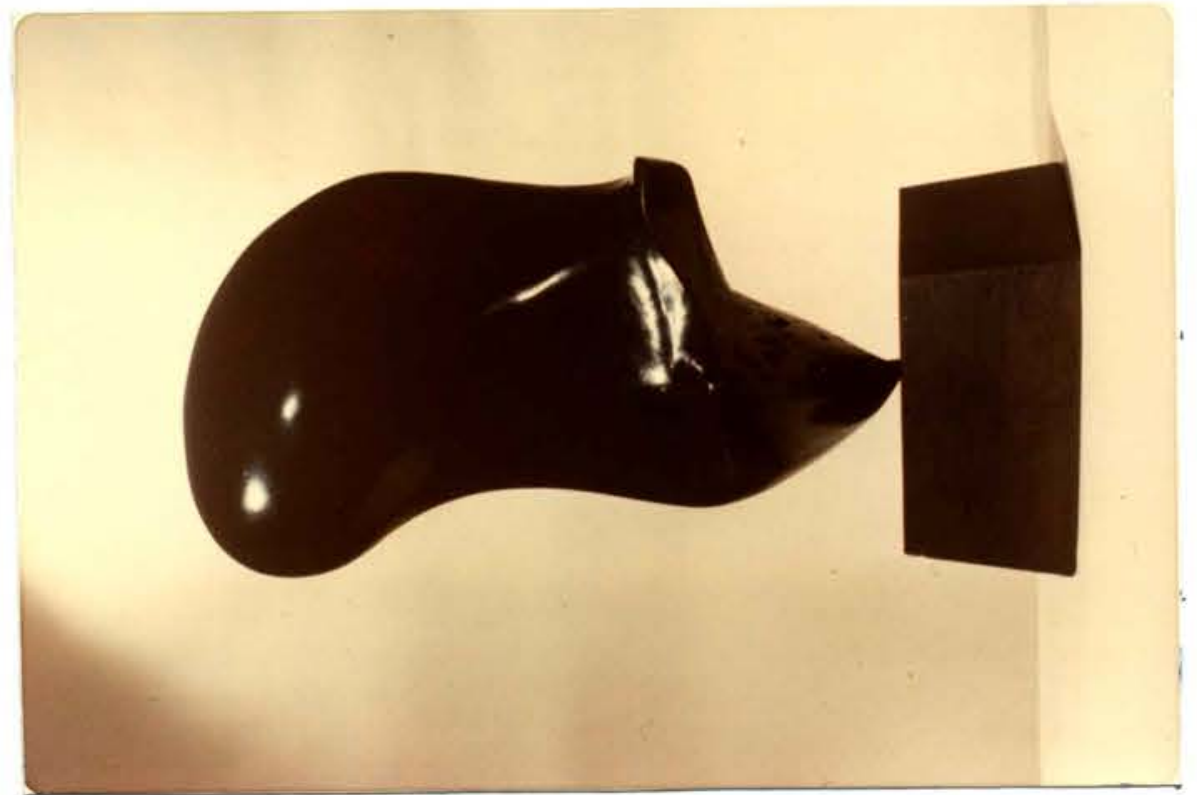

峁

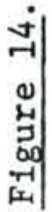


RECLINING FIGURE--OCHRE (F1g. 16-17)

\section{Composition}

The piece has a compositional arrangement based on observations of the relationship between biomorphic (organic) forms and architectural structures (in this case, walls and floors). The two parallel walls connected by a platform create a U-shaped structure which acts as a stage or base which the organic form can exist on and react to. The unyieldIng nature of the geometric stage establishes a point of contrast for the more ylelding organic form. The contrasting elements should be in careful balance.

\section{Material}

Resin was used due to its ability to take almost any color 1maginable. The ochre iron oxtde is a unique color for sculpture. It is warm, yet remains rather neutral. It is a natural colorant, but not one usually seen in sculpture.

\section{Critique}

Some hard edges were used on the organic forms to make them more akin to the geometric ones. Conversely, the geometric forms have been slightly modified to make them appear more organic. These modifications succeed as a compositional device because they help to establish the desired balance in the piece. This sculpture is actually a variation of an early reclining figure piece, but the study of color which resulted in the discovery of the ochre Iron oxide was a major change. 


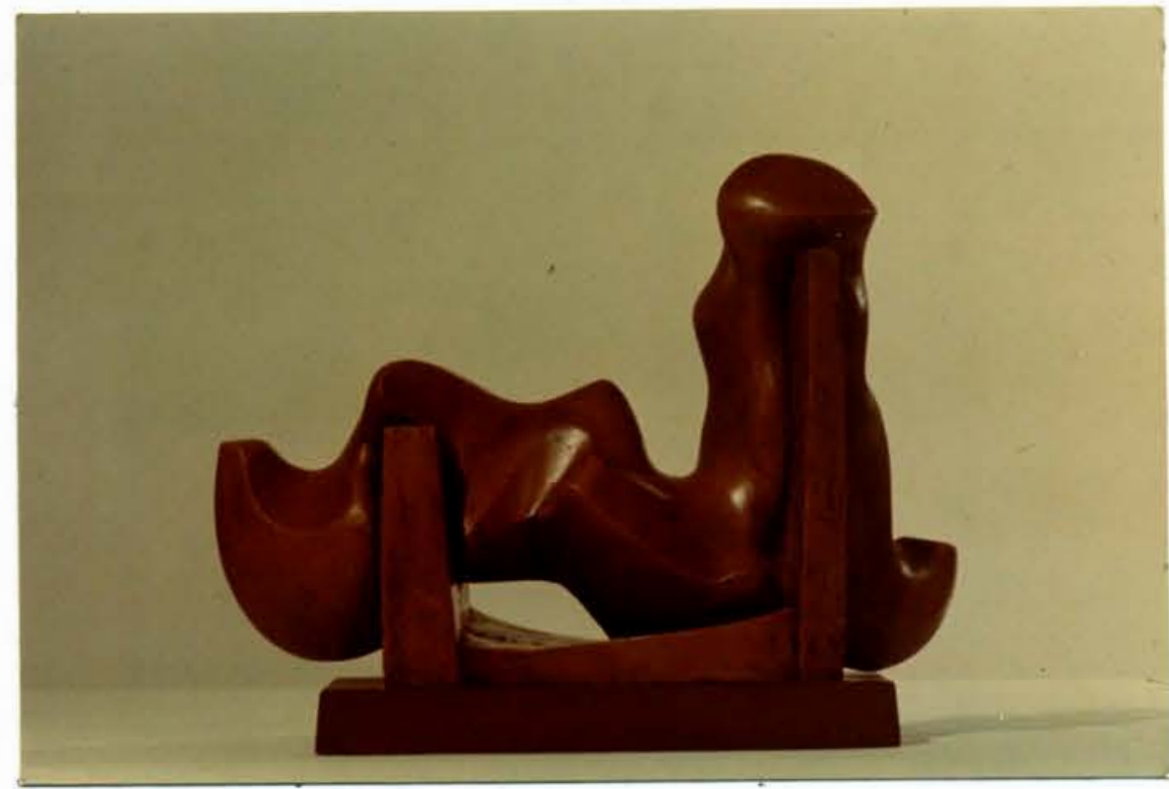

Figure 16. Reclining Figure.

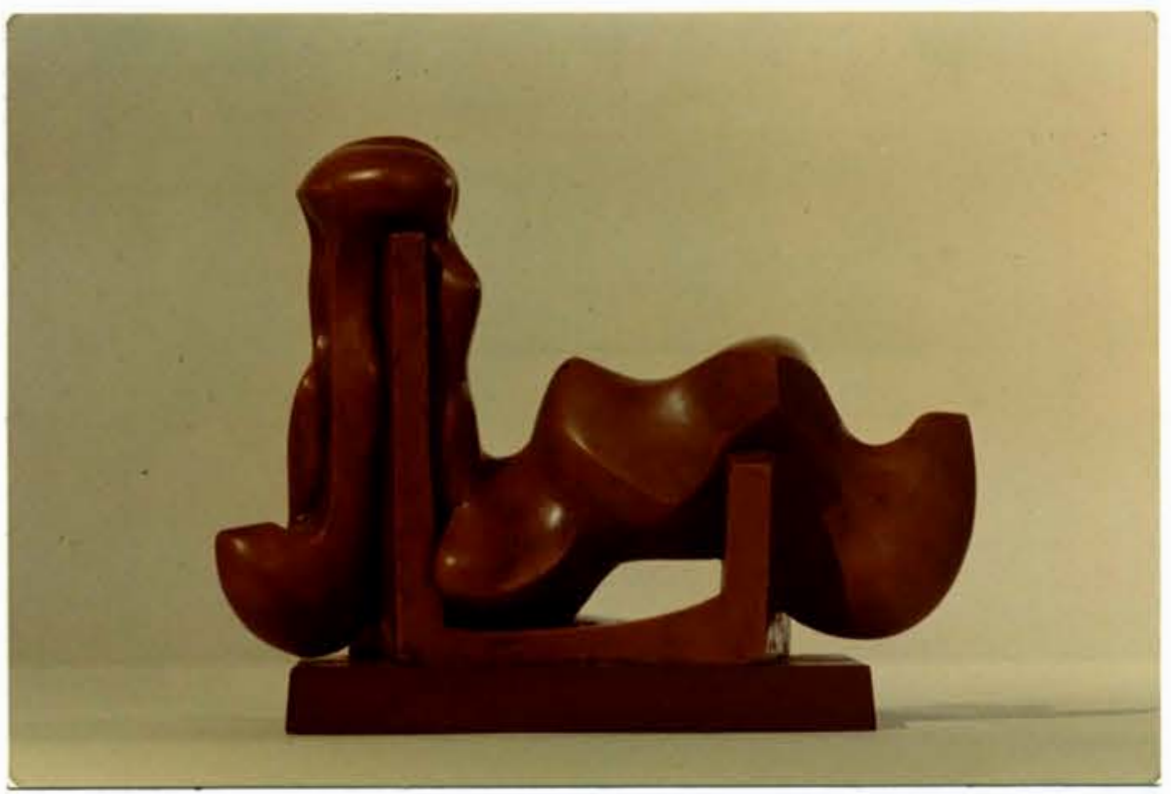

Figure 17. Reclining Figure. Cast resin with ochre colorant. Height 7". 
RITUAL HATCHET (FIg. 18-19)

\section{Composition}

The impetus for this piece was a Chinese jade pendant (FIg. 3). Certain elements have been either altered or deleted to strengthen the Idea and to sult my preferences. This is the first piece where I seriously considered using an incised line. I observed its use on the pendant, and when constructing my version, I found out why it was necessary. The line acts as a preliminary statement of the end of a form. The line is like a shock wave on the surface of a pool of water it announces the perimeter or edge of the form. The incised line exists as a soft statement that reverberates and mirrors the edge of the form. The edge exists as a hard statement.

This plece is also the first that has had a band of organic forms held between geometric forms.

\section{Material}

In attempting to add the dimension of color to my sculptures, I cautiously began to use earth colors like red 1ron oxide. I wanted the color to be part of the sculpture itself and decided that polyester resin was the most flexible of materials.

\section{Critique}

This is a major piece in that it contains three major innovations which are developed in later works: 1) the use of a band of biomorphic forms pressured between two geometric shapes; 2) the use of inclsed Iines, and 3) the use of color (red iron oxide) other than lamp black in the resin. 


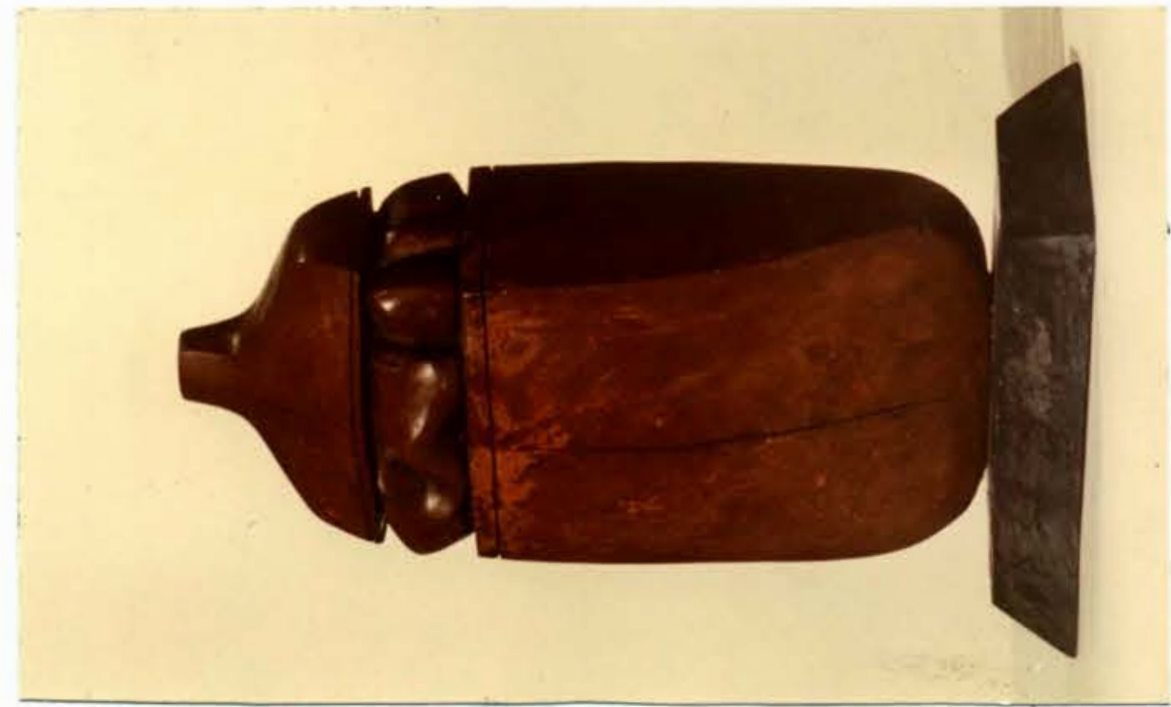

点过

H

L

तै

不

i

ن

式

幽

-1

帘

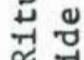

덧

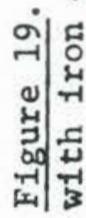

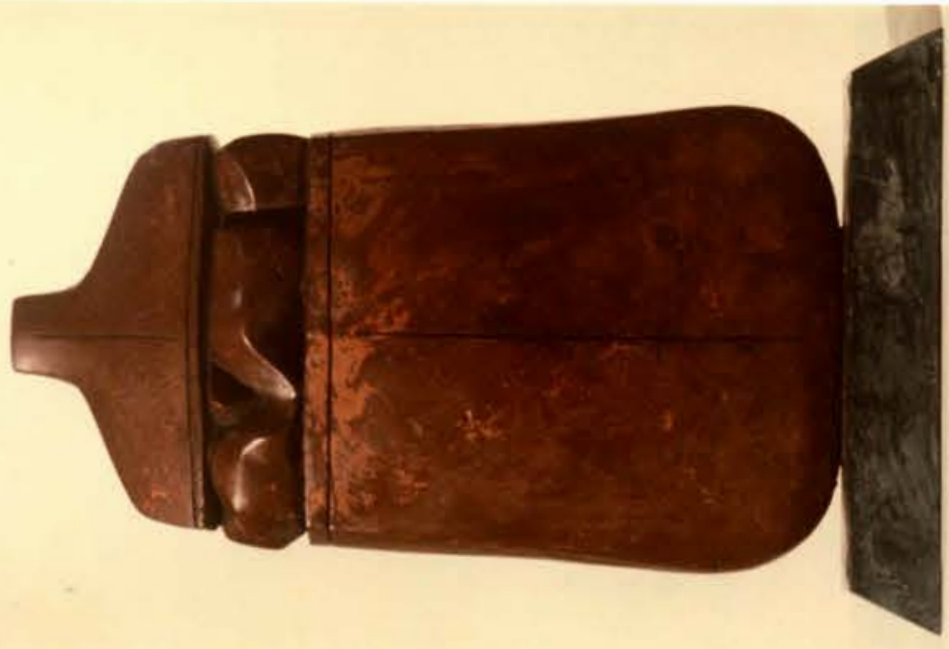

ن

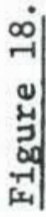


RITUAL DISC (FIg, 20-21-22)

\section{Composition}

The basic Idea for this piece was derived from the Chinese P1 Jade D1scs. While working on the Ritual Hatchet, I became interested in the relationship between geometric surfaces and organic forms. The wheelshaped P1 Disc has a natural completeness, and it is a form which has existed throughout history. It was an extremely difficult problem to Introduce an allen shape to this basically perfect form. The strength of the geometric flat surface tended to overpower the organic form and had to be altered somewhat. To break up the strong disc shape, one side was almost totally divided by a horizontal line, the other side by

a vertical line. These are strong divisions, yet they seem basic to man's perception of space. The divisions not only subdue the strength of the pl form but also supply an additional point of contrast with the organic form. I wanted to balance a large, flat, passive form with smaller, curvilinear, more active forms.

\section{$\underline{\text { Materials }}$}

Polyester resin. Due to lack of confidence in using color, I also cast this piece in red fron oxide.

\section{Critique}

A long, low geometric base was chosen for this plece. The base disturbs the viewing of the sculpture as little as possible. The thinness of the sculpture created problems when securing it to the base. To satisfy this problem the bottom part of the disc could have been made wider. The base would then be more stable and the lower portion of the sculpture could catch more light. 


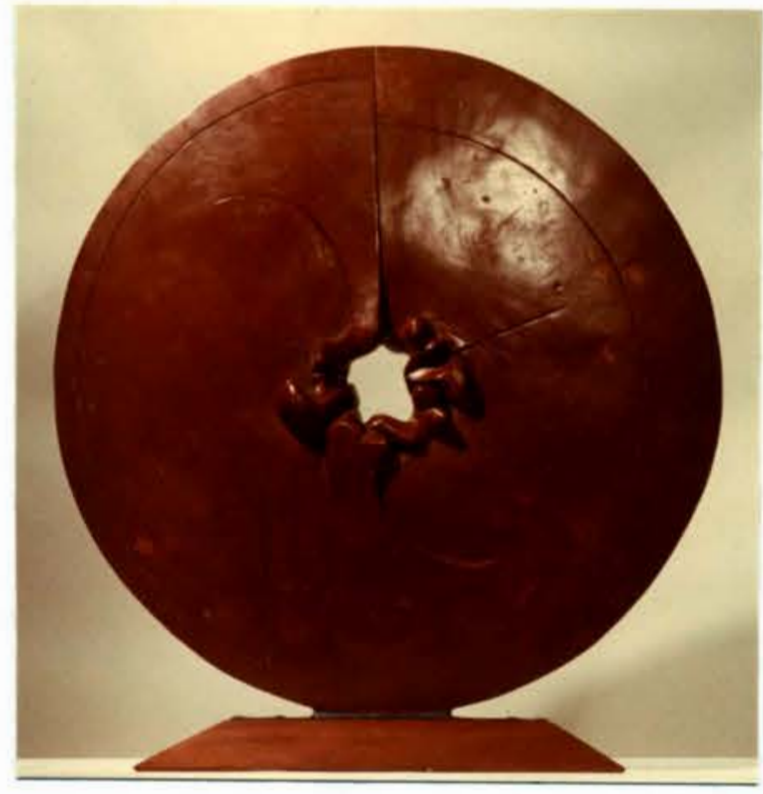

Figure 20. Ritual Disc.
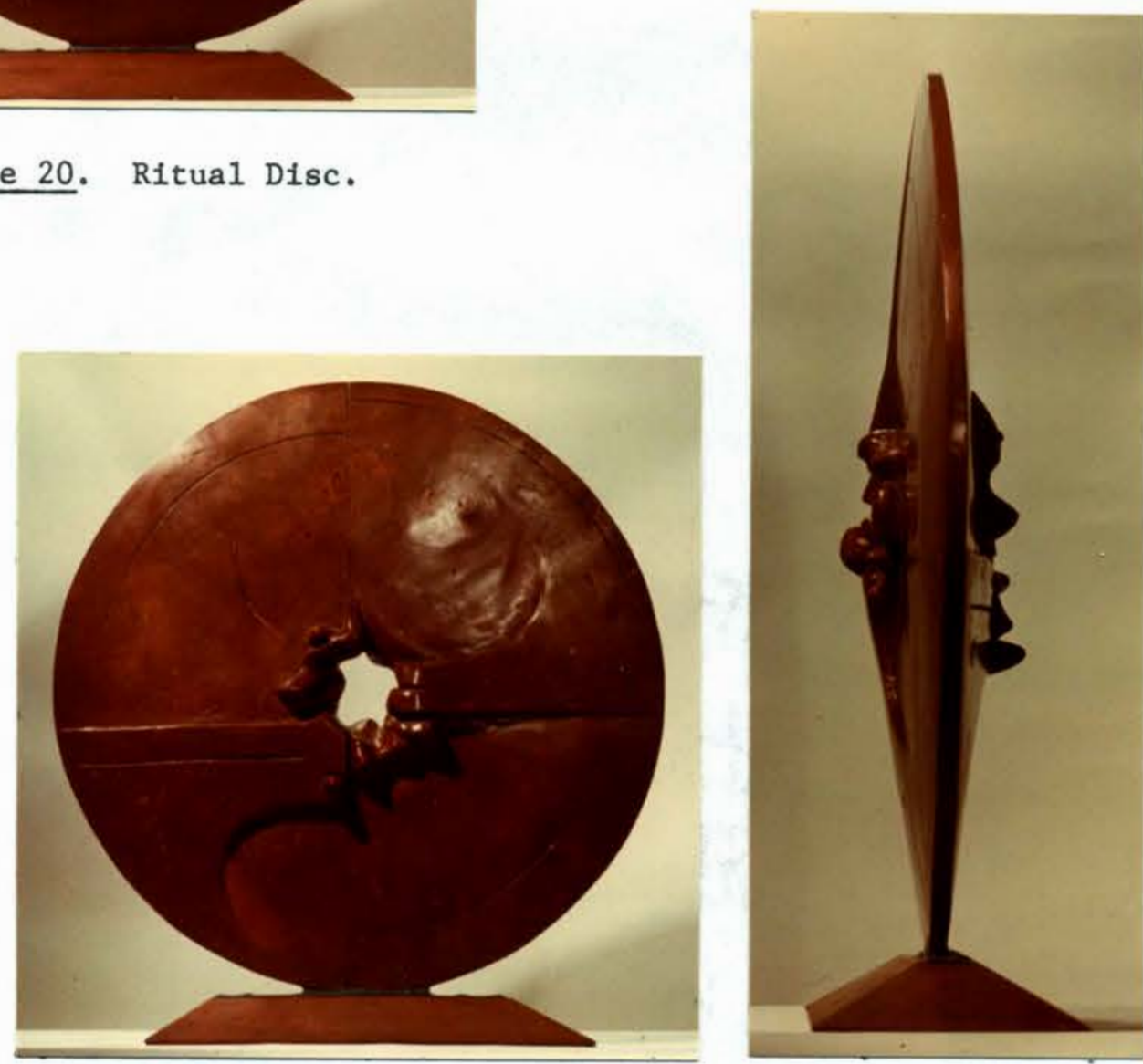

Figure 21. Ritual Disc Cast Resin. Diameter 30".

Figure 22. Ritual Disc. 
RECLINING DISC (FIg. 23-24-25)

\section{Composition}

After having seen a reproduction of one of Isamo Noguchi's reclinIng sculptures, I decided this was an Interesting approach to a basically flat surface. My sculpture has a formal front like the entrance to a Mayan temple. The piece is the basic pi form. The compositional problems that occurred in the upright standing $\mathrm{p} 1 \mathrm{disc}$ are tempered by having the surface reclining, thus mellowing the impact of 1 ts geometry. I used an Inclsed line to link organic forms to each other and to the larger geometric forms. Another concentric line runs to the edge of the $\mathrm{p} 1$ form. The disc has a slightly curvilinear surface and reminds me of the curve of the earth. In this curvature there was a good opportunity to create a perspective 1llusion. The concentric incloed line is set off center. The line at the front is wider and progressively narrows to the opposite point in the back of the plece. Thus, in true perspective fashion, an 1llusion of greater depth is produced.

\section{Mater1al}

My Interest in problems of composition surmounted my interest in problems of color, so I reverted to the use of lamp black in resin.

\section{Cr1t1que.}

Black instead of red colorant was used mainly due to the similarity of the two disc sculptures. The plece is strongest from the front and top. It is weakest from the two sides. The sculpture might be strengthened by organic forms reaching toward both sides from under the disc shape. 


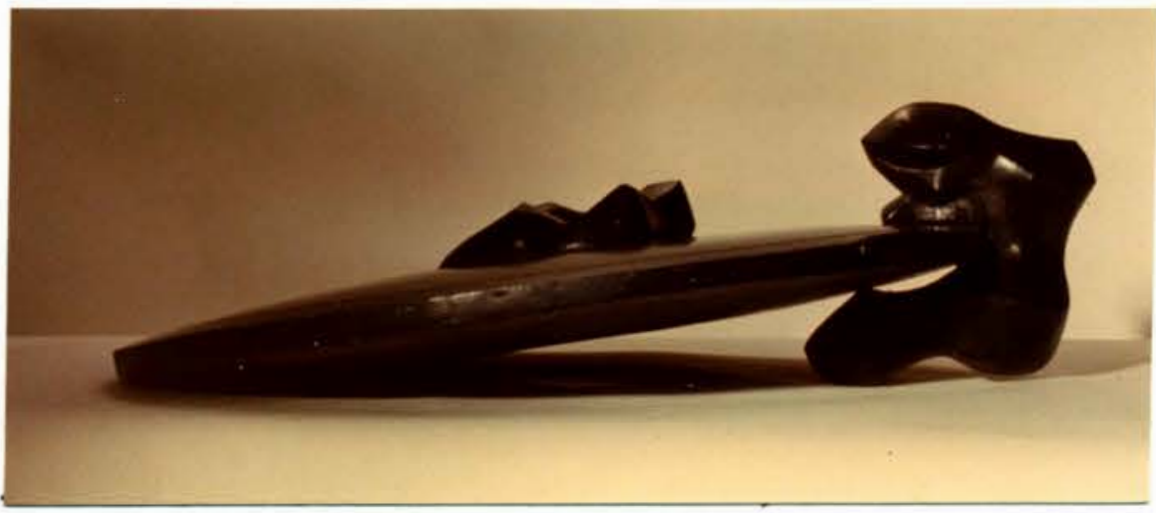

Figure 23. Reclining Disc.

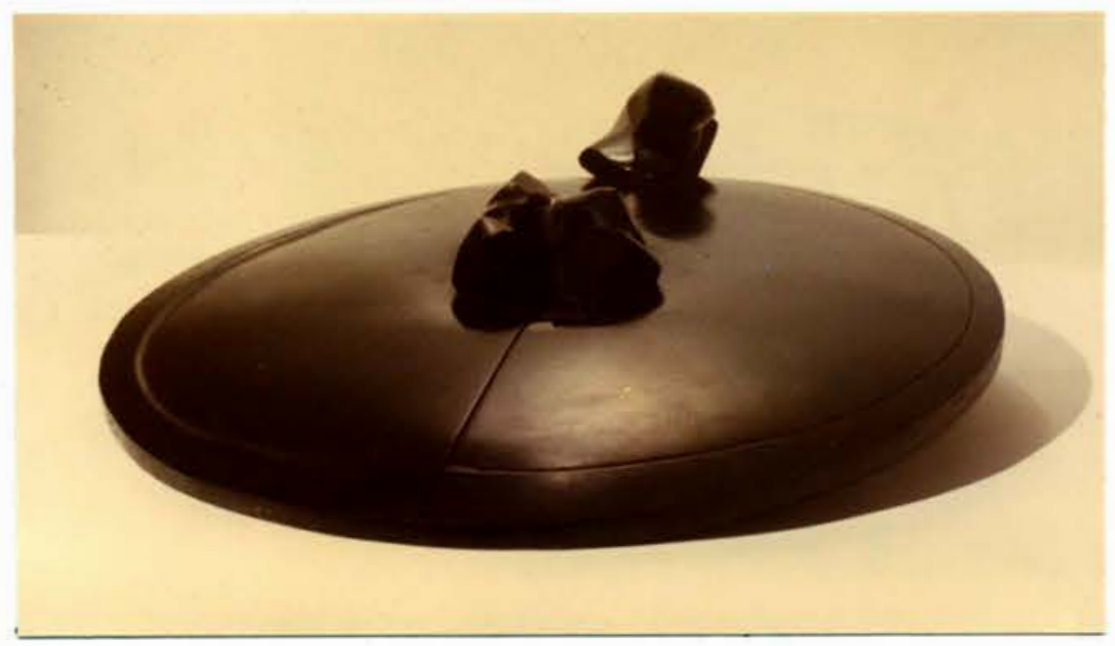

Figure 24. Reclining Disc.

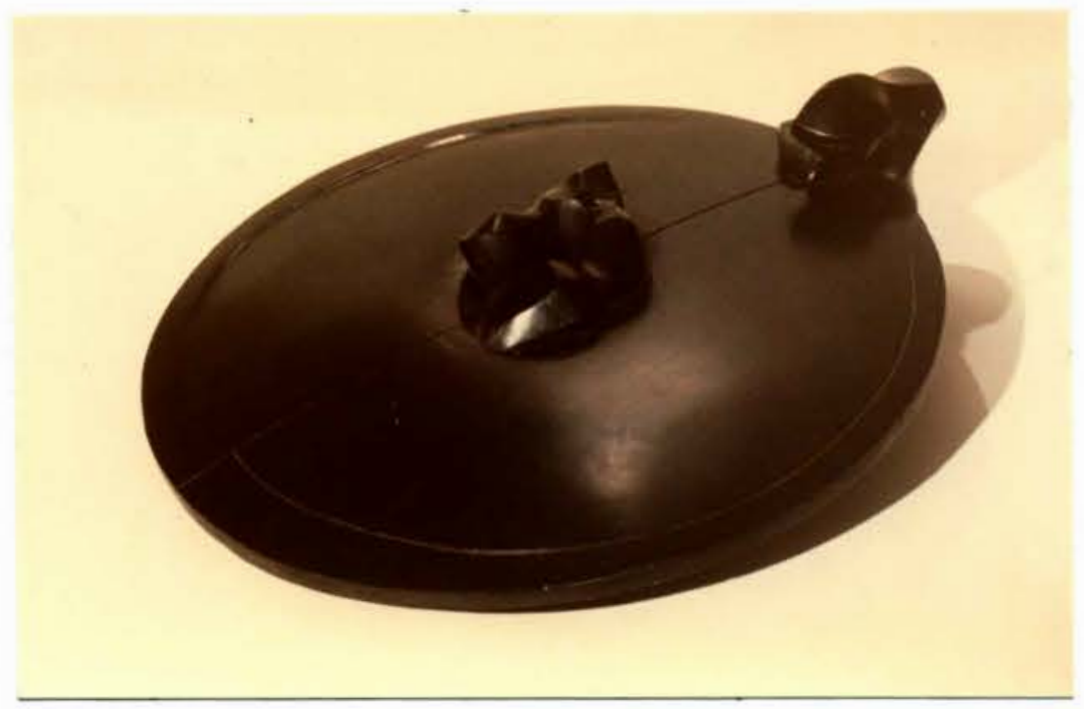

Figure 25. Reclining Disc. Cast Resin. Diameter 28", height 10". 
MONOLITH 73 (FIg. 26-27)

\section{Composition}

Monolith was Inftially concelved from the organizational arrangement of a clty map. On such maps, block and street divisions describe IImftations on space in a manner not unlike the composition of a paintIng or sculpture. Similarly, in Monolith, Inclsed lines limit the number and extent of the organic forms. A second concern was the height and number of elements which can be seen in progressions from lower to higher forms, and from few to many elements.

Another progression, usual in painting but seldom specifically explored in sculpture, is the sequence from dark to light. In Monolith, the organic forms vary from deep, dark caverns below the surface, to forms that exist above the surface, to openings that pass completely through the structure and appear to the viewer as bright spots of 1 ight. The Incised lines both embrace and subdivide the form progressions. The lines are like the center lines which divide and direct road trafflc, punctuated with stops and curves. At t1mes, they also form block-11ke elements, reminiscent of stone masonry construction.

The Impressionists noted the similarity in function of the human eye and the camera: when efther focuses on an object, other objects outside of that focal plane are out of focus. So the eye is continually focusing and refocusing on different levels of form. This 1dea influenced the grouping of elements in Monolith; contained within some spaces are a deep dark cavern form, a form ralsed on the surface, and a space that passes completely through the main structure. The center of the main structure is approximately at eye level. So looking through 
the openings gives the viewer a full range of perspective views below, at, and above eye level.

\section{Materials}

Black cast resin and polished, welded steel.

\section{Critique}

The oteel base is from the battered pylon form of ancient Egypt. The structure is a very complex arrangement of elements. I do not at this point see any aspect that I would wish to change. 


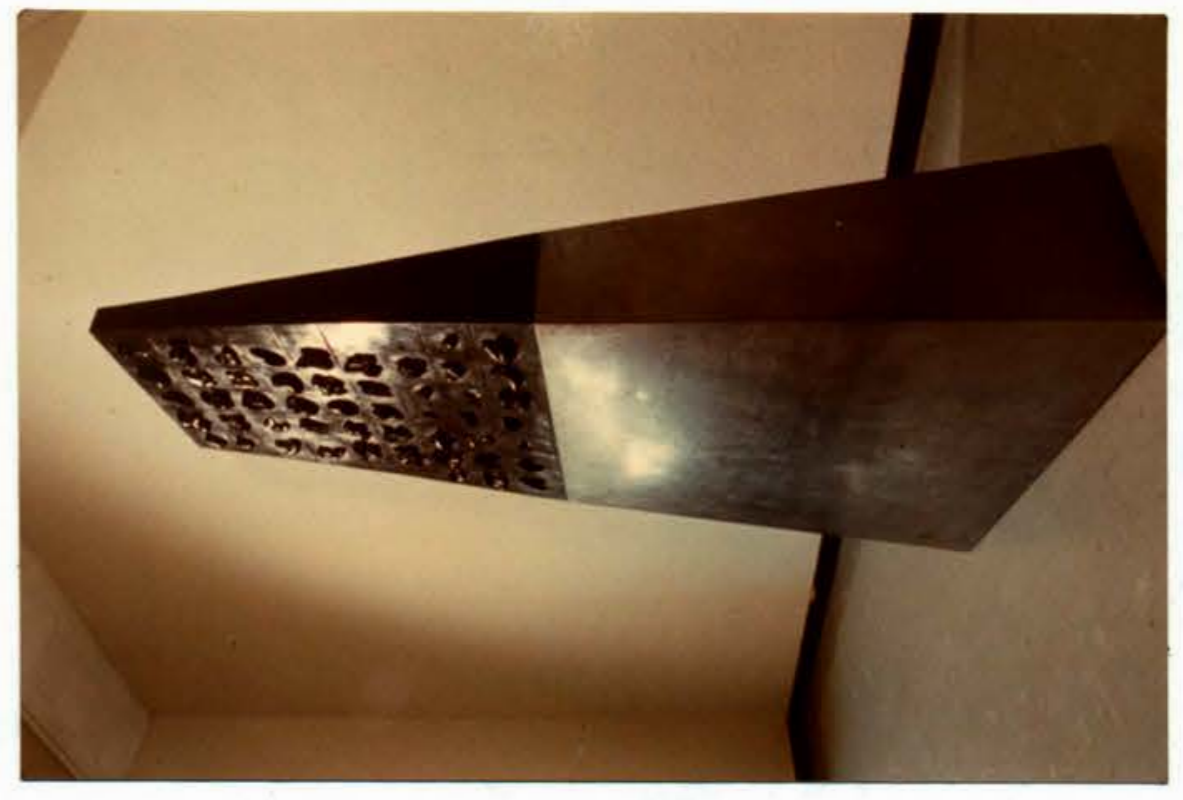

ֻ

$=$

$\stackrel{n}{\infty}$

돈

-1

등 퍼

일

.

심

.

ક્ષ

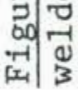

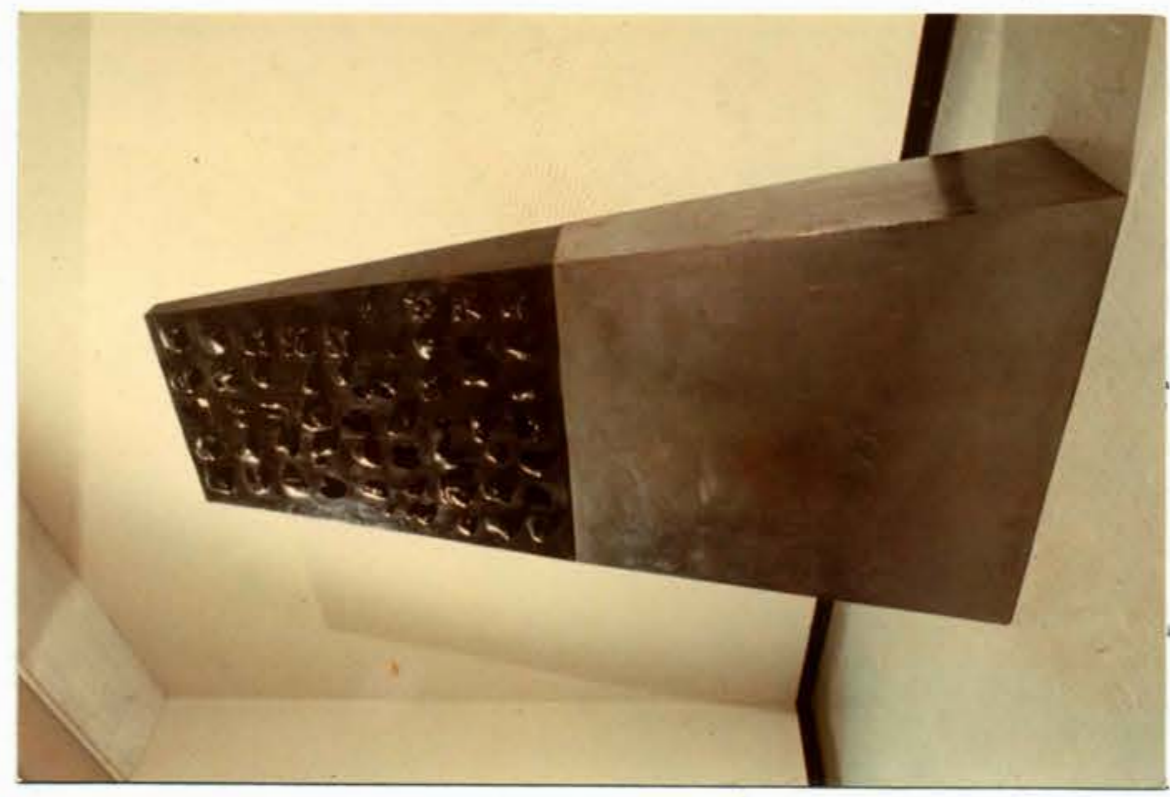

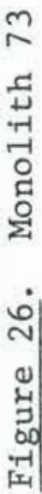


TRI-SPHERE (F1g. 28)

\section{Composition}

The Tri-Sphere is related to Ritual Hatchet in its use of a band of organic forms. The spherical form is derlved from the pi disc form. The sphere is an enormous mass. I decided that a division slightly below midpoint would increase the feeling of mass pressing down on the thin band of blomorphic forms. The larger top form is hot red since red is the most emotional color I could think of. The bottom form which supports the blomorphic elements is blue, the quietist color I could think of. The blomorphic forms are a pale bone wh1te.

\section{Material}

Cast resin for flexibility in coloration.

\section{Critique}

The feeling of pressure on the blomorphic forms could be increased by Increasing the size of the sculpture. Almost without limit, the larger the sculpture, the greater the appearance of pressure on the organlc forms. Joseph Albers made two dimensional color studies and changed his concentric square format very little. The Tri-Sphere and Blue Sphere come closest to his concept of evaluating color combinations using vastly similar shapes. The sphere is a self-completing entity which I have divided into three horizontal areas. In the TriSphere, the colors, with distinctly different natures (mainly primary colors), expand these divisions. In the Blue Sphere, color (11ght to dark) is used in a vertical movement, and the combination of form division movement and color movement creates a criss-cross composition with emphasis at the center. 
BLUE SPHERE ( $F \perp g, 29)$

\section{Composition}

The composition is almost exactly the same as the Tr1-Sphere. They were cast from the same mold. I did alter and rework the biomorphic forms making them smaller and more complex to vary. the size ratio of geometric to blomorphic forms. I decided to use color to enhance the downward thrust. The color progresses downward in three stages: medium blue, to blackish-blue, to a bluish-black.

\section{Material}

Cast resin for flexibility in coloration.

\section{Critigue}

Since the active color of red was chosen as the predominant color for the Tri-sphere, I wanted to make a sphere with a quiet color which was blue. I thought that a predominantly blue or blue-black might add a somber, night-like atmosphere to the sculpture. The blue coloration (light to dark) is so subtle that few people are aware of the variations. In the mixing of colors I forgot to allow for the shadow cast by the sphere which mutes even more the subtle color variations.

In trying to create a base form for the blue sphere I attempted a square shape. The form seemed to be too massive and always in direct opposition to the sphere. I had the base chromed and polished to see if the mirror surface might visually dissolve the base. The mirror surface did lessen the surface mass, but the problem was replaced by a visually active surface that draws the eye away from the sculpture. 


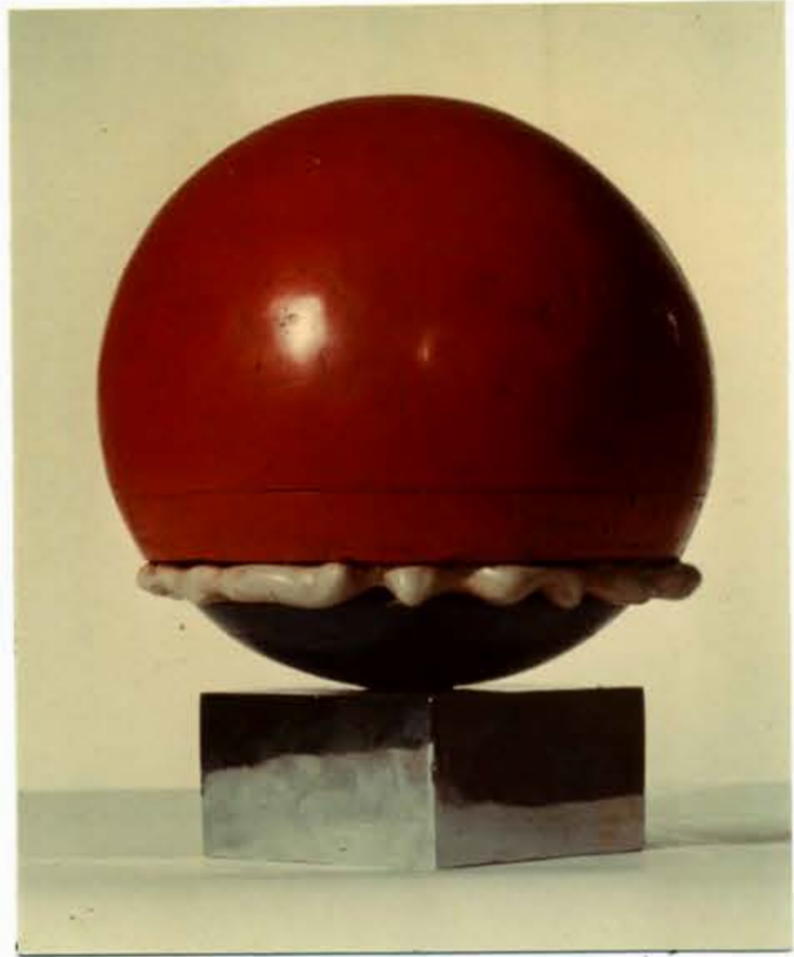

Figure 28. Tri-sphere. Cast resin. Height 12".

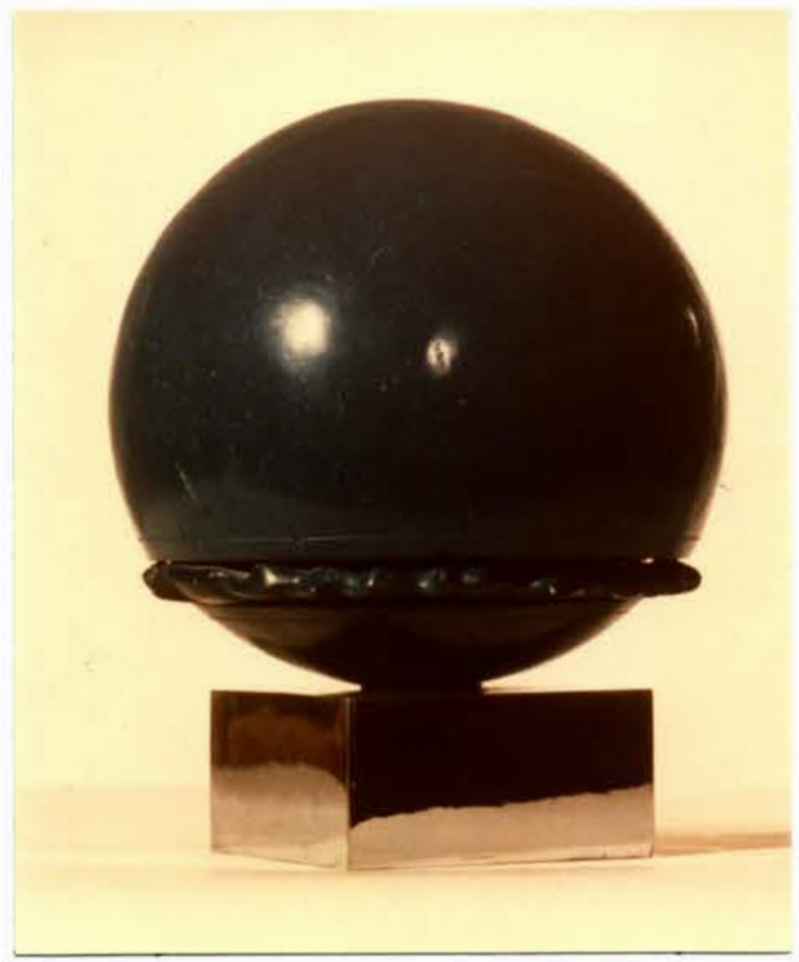

Figure 29. Blue sphere. Cast resin. Height 12". 
MOTHER NATURE'S SILVER SEED (Fig. 30)

\section{Composition}

The silver seed is an enlargement of the ideas explored in the Tri-Sphere and the Blue Sphere. With the form enlargement there can be greater latitude in the form development. The biomorphic forms take on intestine-like configurations. I decided to attempt to capture the Images of spherical forms (like pearls, moon and star forms, and cloud forms). I decided that blue was a successful color for the lower portion of the sphere, except that I changed the basic blue to a pearlescent blue to compliment the pearl white of the top portion. To make the blomorphic forms more convincing I cast them in fleshy tones. To help eye movement down from the large white hemisphere to the organic forms, the organic forms had to extend beyond the edge and travel along that edge to set up an association of surface to surface. I used a line that paralleled the form's hard edge to soften the surface-to-hard edge transition.

\section{Material}

Polyester resin was used for flexibility in coloration. A liquid pearlescent pigment was added to give the forms more vitality. Steel rebar was added for major reinforcement. Expanding polyester foam was used as a secondary interior reinforcement.

\section{Critique}

Its size allows the viewer to get more involved with the forms and increases the feeling of pressure on the organic elements. I tried several base shapes to go with the spherical shape. In another attempt 
to solve the base problem I constructed a square tube frame base. The Idea was to lessen the surface area of the base. Th1s base is an Improved solution yet not completely satisfactory. The tube structure does not seem visually strong enough to support the sphere's mass, thus, 1t negates its mass. The tube base could be Improved if the bottom portion was wider and the vertical bars had more angle as if. they were flexing under an extreme weight. 


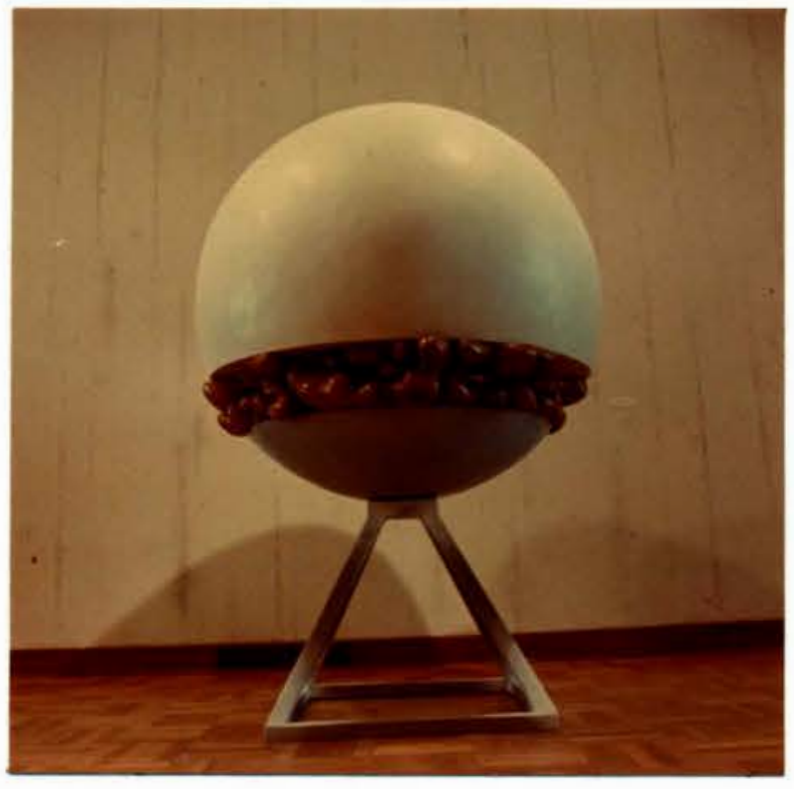

Figure 30. Mother Nature's Silver Seed. Cast resin. Height 96". 
DIMENSION DISC (FIg. 31-32)

\section{Composition}

Th1s sculpture $1 \mathrm{~s}$ related to both previous $\mathrm{p} 1 \mathrm{~d}$ lsc forms. From one piece 1 t derives the division of geometric form by strong verticals and horizontals, and from the other 1t derives an expansion of biomorphic forms over the surface of the piece. Man percelves size by dimension of vertical and horizontal axis. So a diamond shape will appear longer than a square of exactly the same size due to the fact that its vertical and horfzontal dimensions are greater. This observation led me to try to make a sculpture that would appear to alternately grow and shrink as the viewer moved from side to side. So I decided on the p1 shape with a square on one side and a diamond on the other. Dividing the geometric space into different planes created platforms that biomorphic forms could sit on or lie against.

\section{Mater1a1}

Resin was again used so a colorant could easily be applied. I chose green, partly because it is a color seldom seen in abstract art. Green is seen in bronze sculptures as a patina, but seldom in the intensity I would be using $1 t$.

\section{Cr1t1gue}

I think that the intended 1llusion works. I think it is obscured by the number of forms that occur on the surface. A larger sculpture might Increase the viewer's ablitty to observe the 11lusion. 


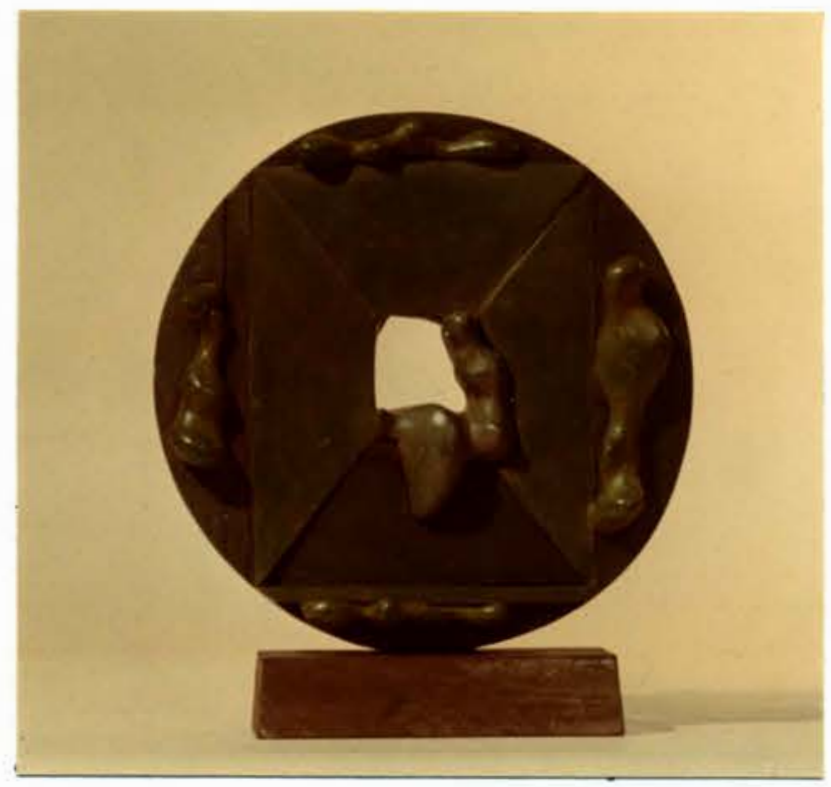

Figure 31. Dimension Disc.

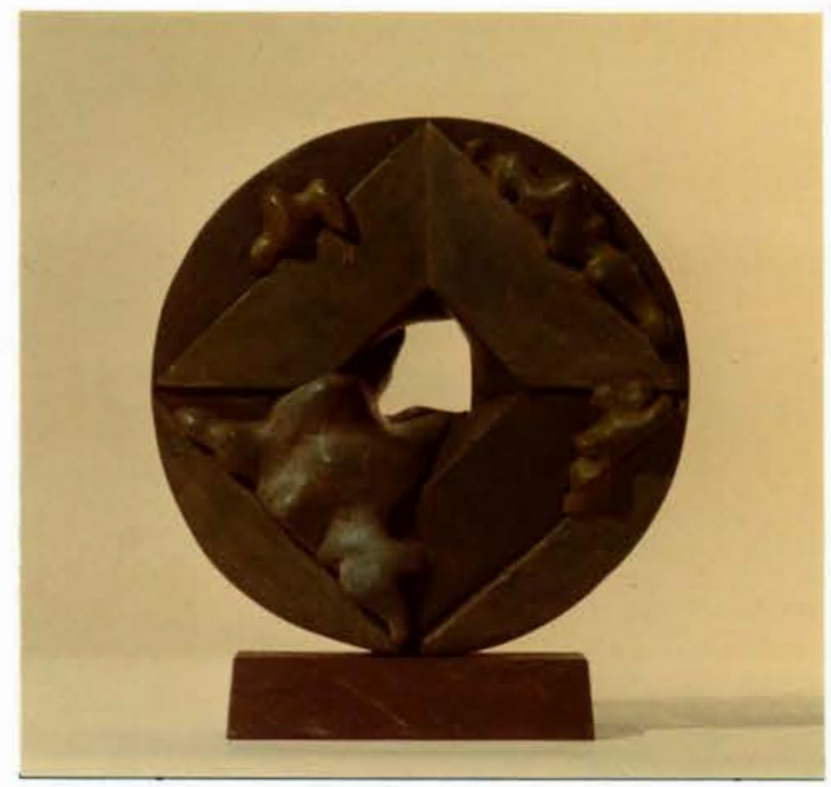

Figure 32. Dimension Disc. Cast resin. Height 10". 
HARLEQUIN (F1g. 33-34)

\section{Composition}

The Harlequin can be seen as a circular composition not unlike the disc pleces. Once again I was interested in an aspect of space. I was interested in a sculpture's ability to envelop and to control as much space (negative space) as possible. One obvious correlation would be to East Indian multiple-armed figure sculptures. Figures obviously have hands to end their appendages, but how could I end the appendages of an abstract sculpture? The format is generally the same as that of the disc sculptures. The outside is basically geometric, and the inside is organic. My answer, then, was to enlarge the end of the geometric appendages. From the center they would bulld and enlarge to a strong geometrical finish. The main problem was to balance the positive and negative forms. To reinforce the nature of the forms I decided to use blue for the geometric areas changing progressively through violet, red, and orange as the forms become organic and warm at the center. There is also a movement from simple to complex.

\section{Material}

Cast resin was used due to 1 ts flexibility in colorants.

\section{Critique}

I believe this is a highly successful sculpture. I think the/plece might be stronger if it was twice as big. This would allow the viewer to interact more directly. 


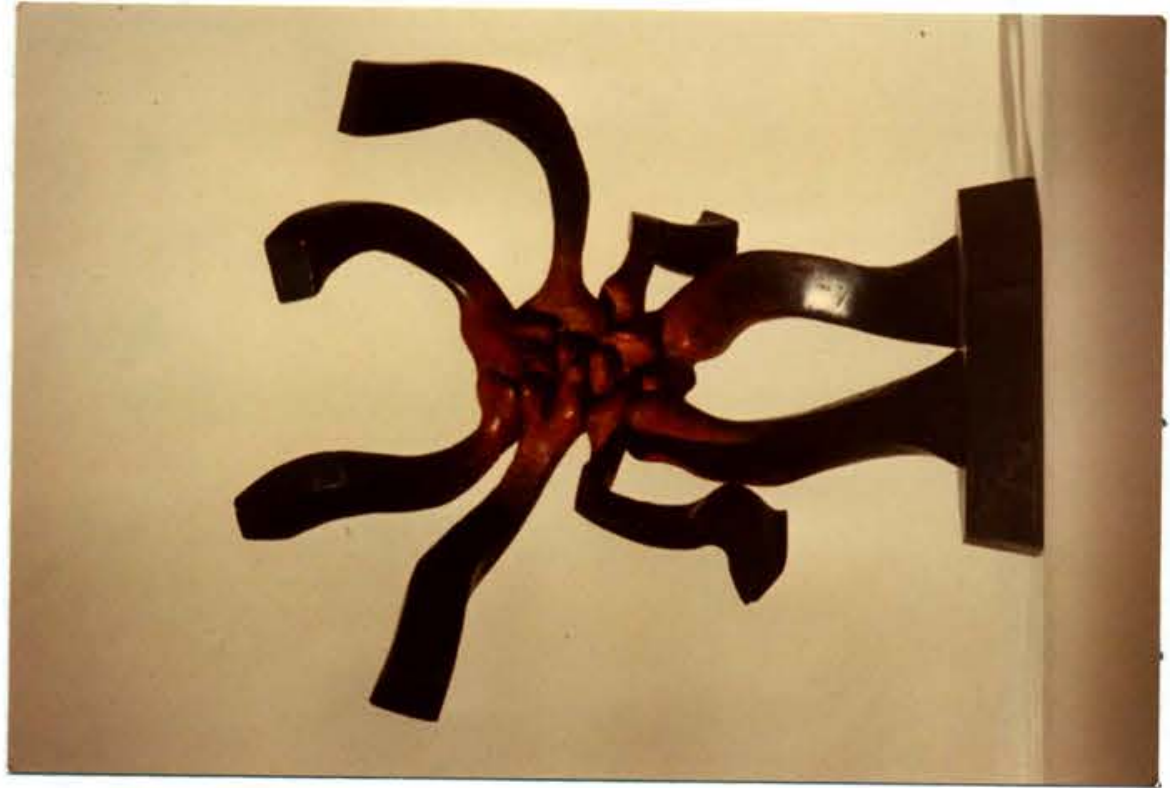

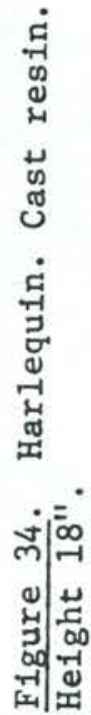

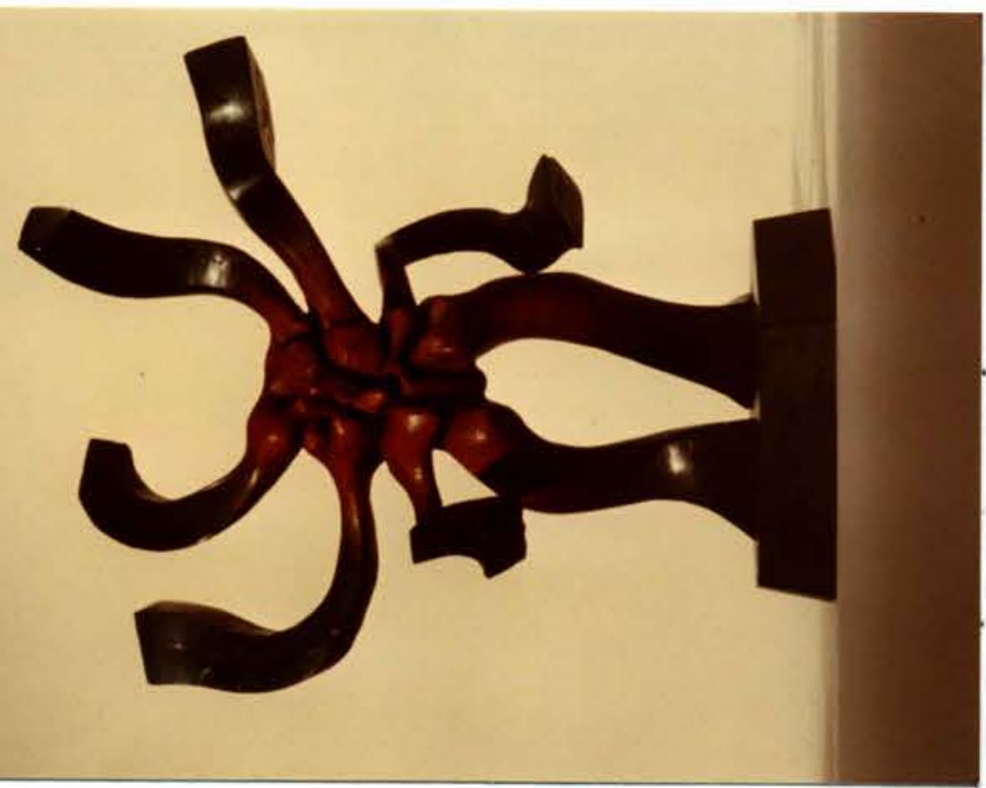

लें| 


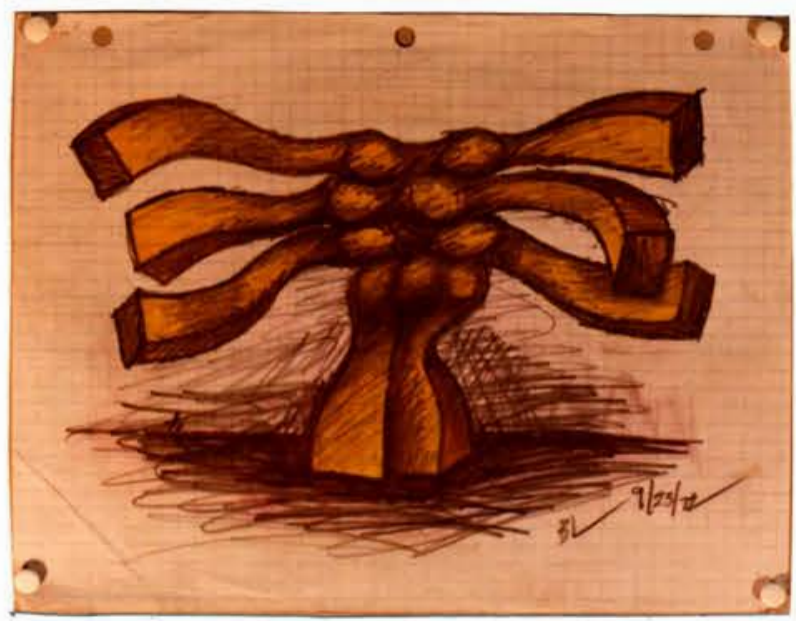

Figure 35. Drawing (1) $9 / 23 / 72$

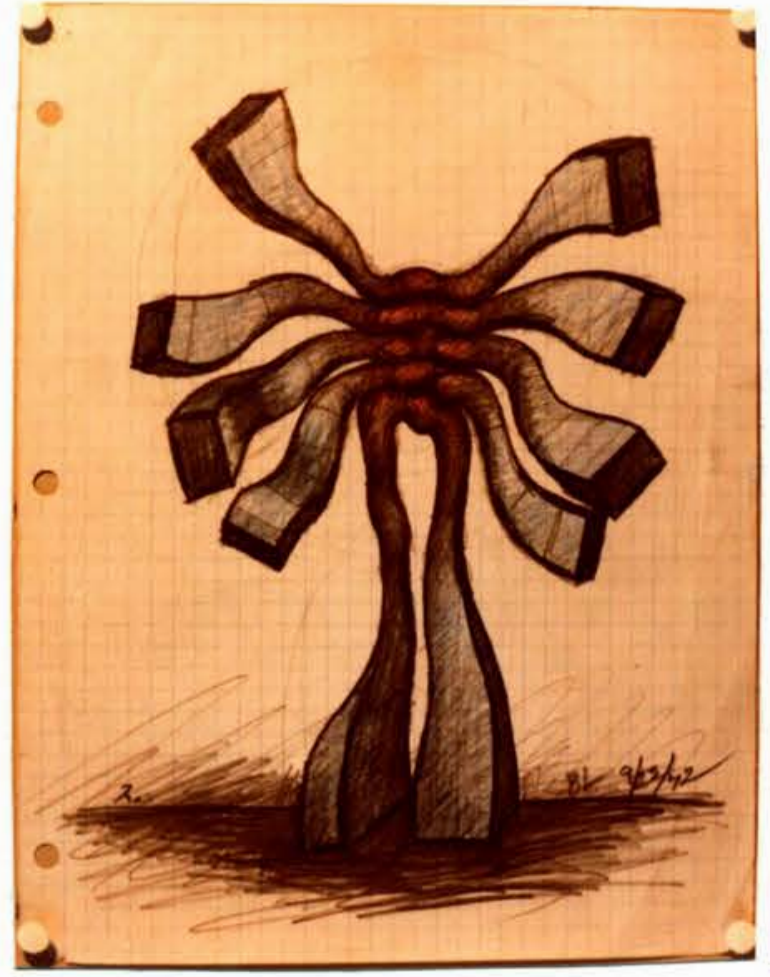

Figure 36. Drawing (2) $9 / 23 / 72$

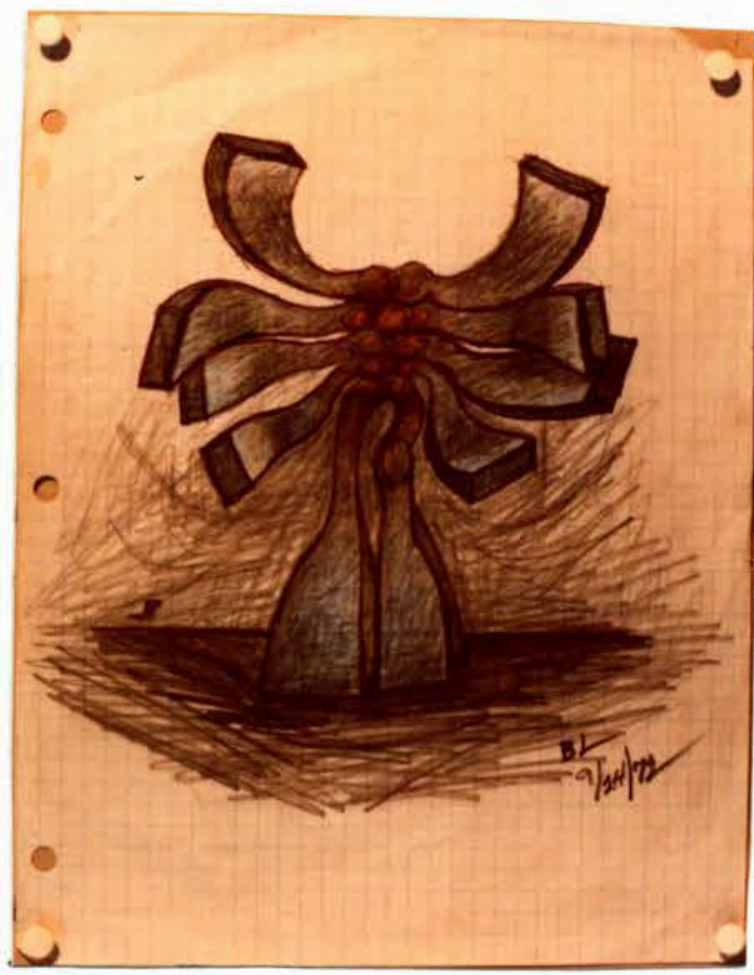

$\frac{\text { Figure } 37}{9 / 24 / 72}$. Drawing (3) 


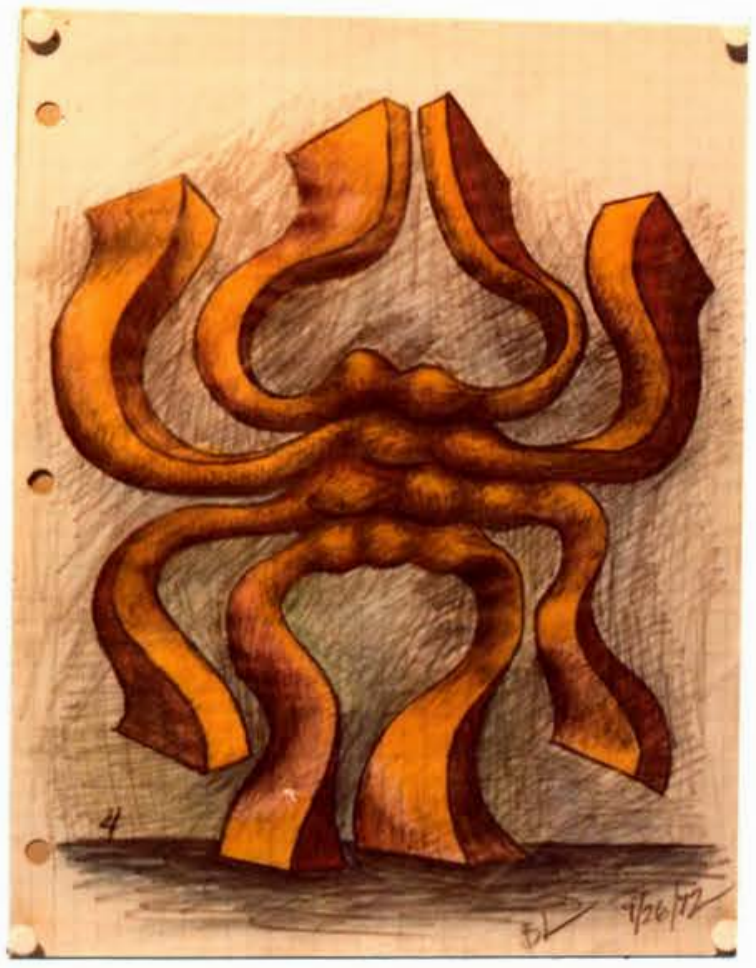

F1gure 38. Drawing (4) $9 / 26 / 72$

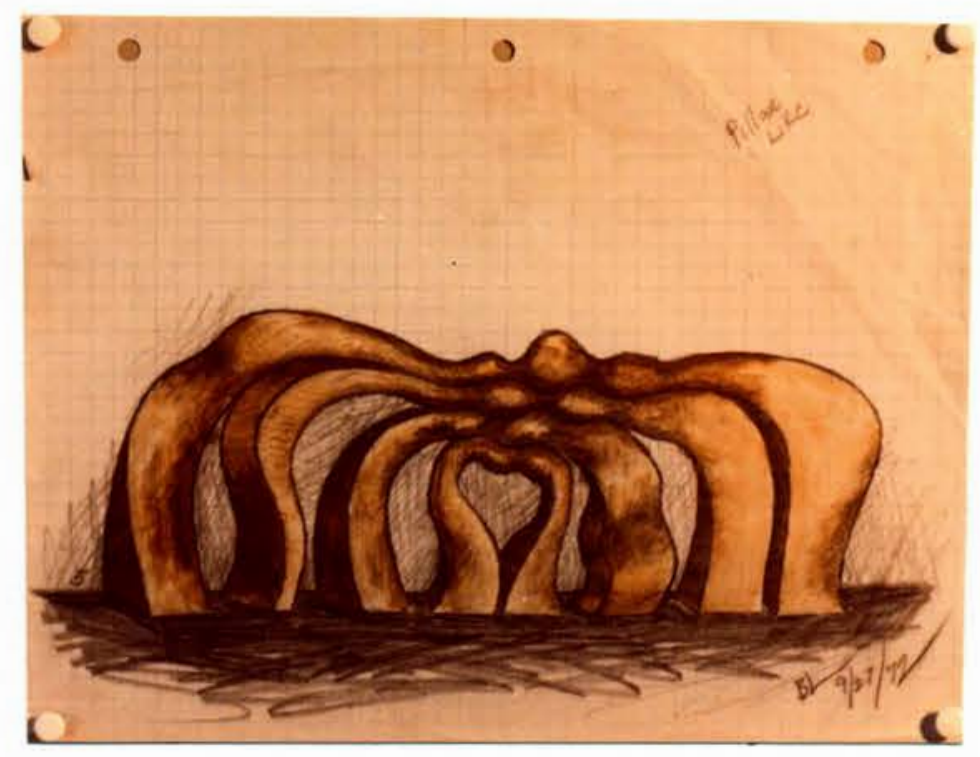

Figure 39. Drawing (5) $9 / 29 / 72$ 


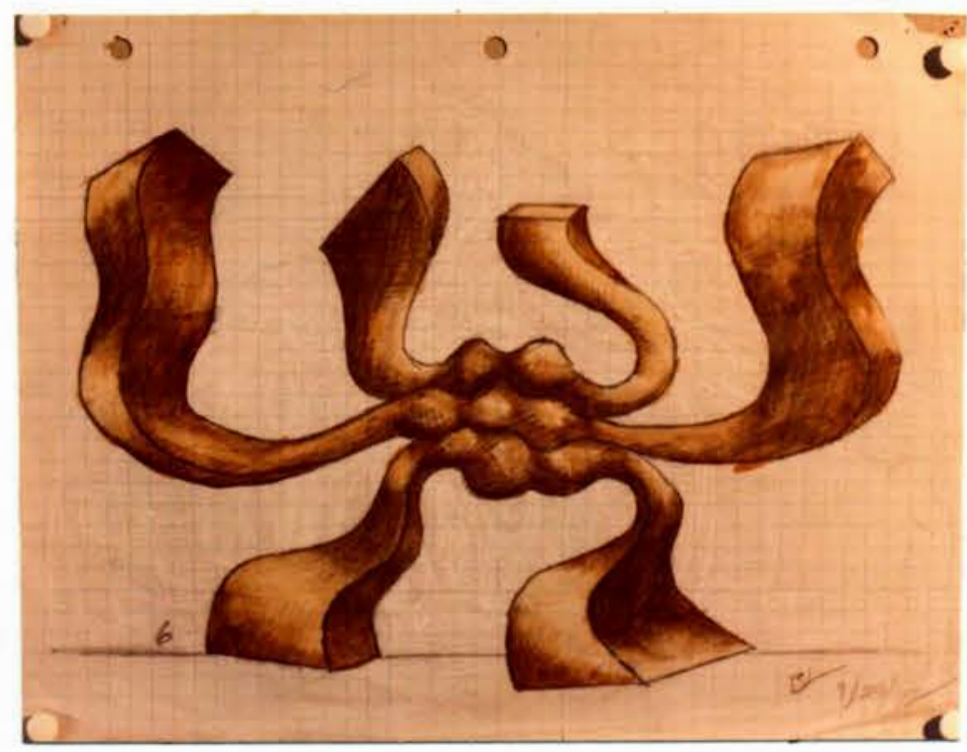

Figure 40. Drawing (6) $9 / 29 / 72$

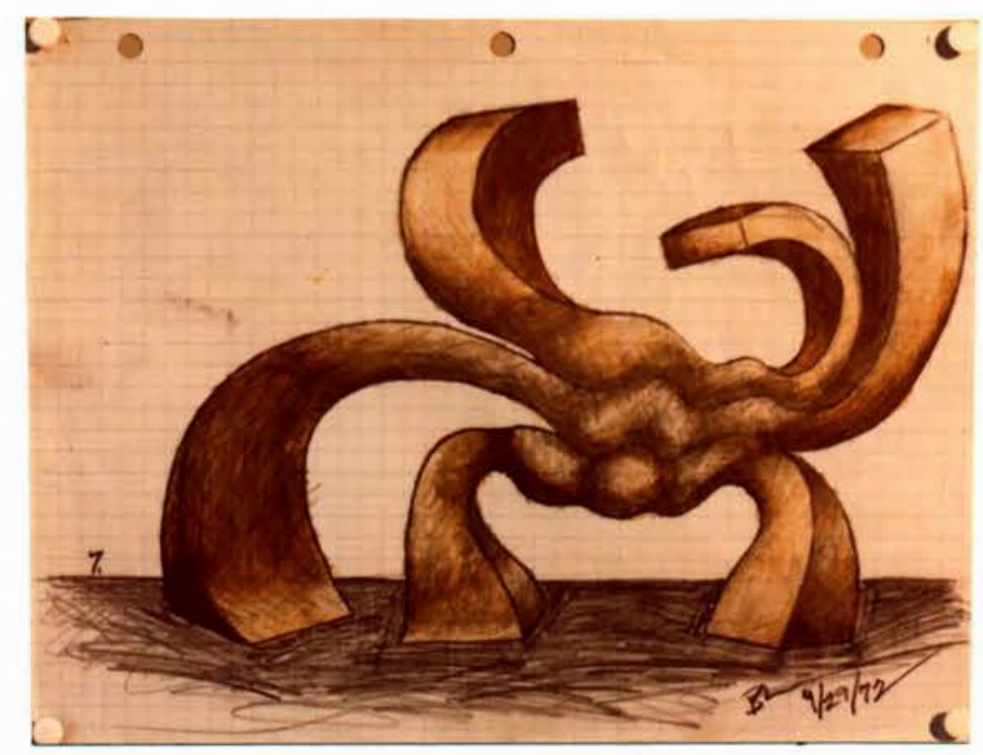

Figure 41. Drawing (7) $9 / 29 / 72$ 


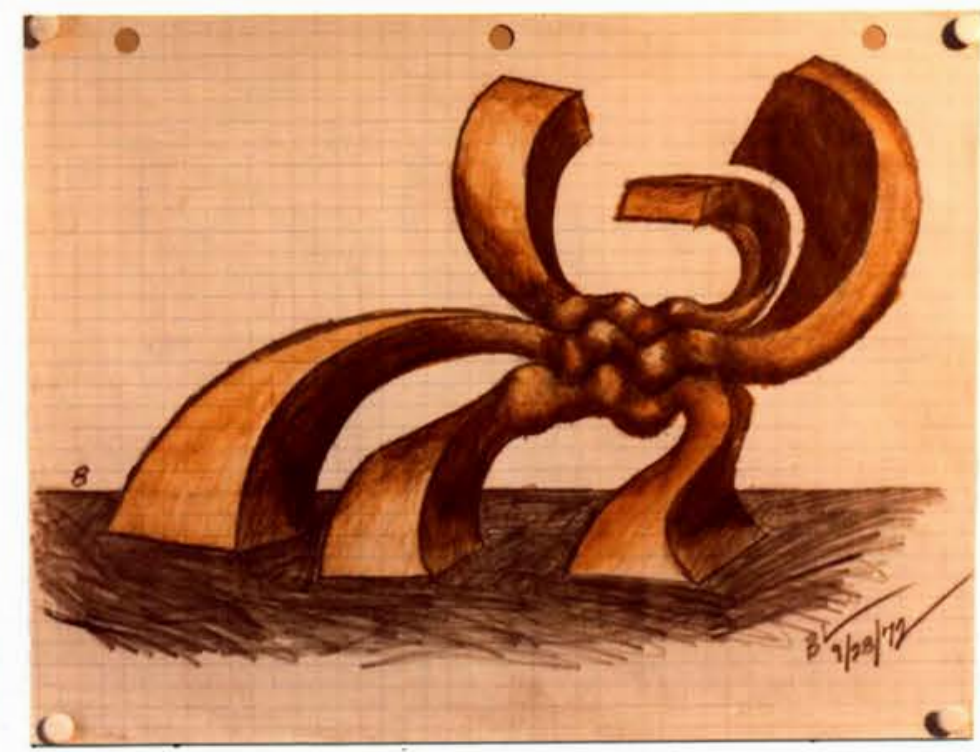

Figure 42. Drawing (8) $9 / 29 / 72$

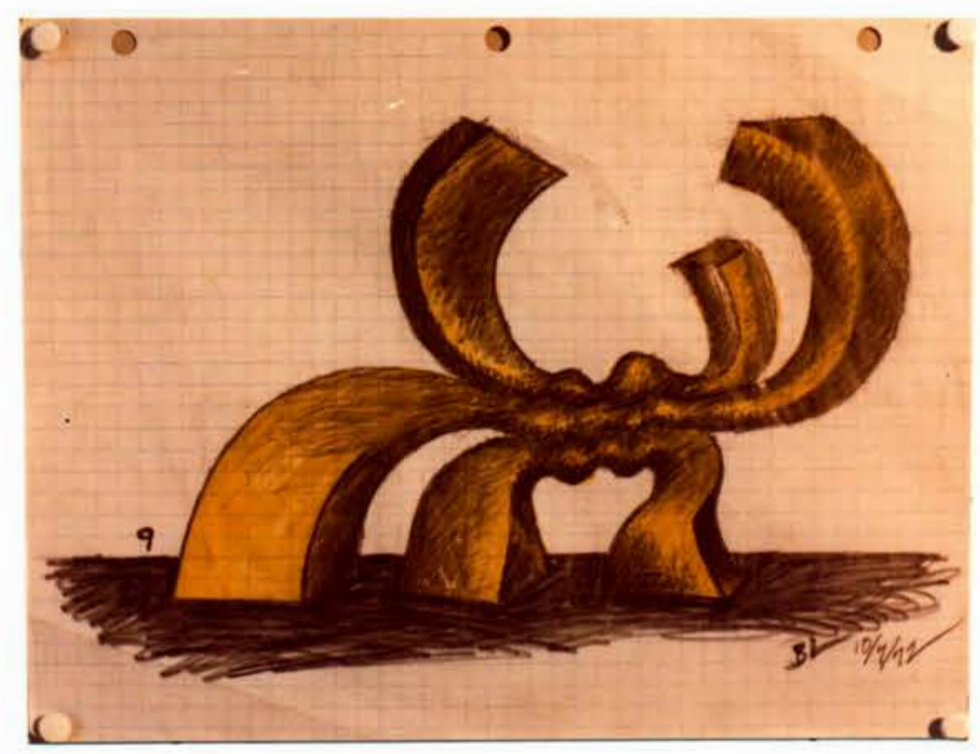

Figure 43. Drawing (9) $10 / 7 / 72$ 


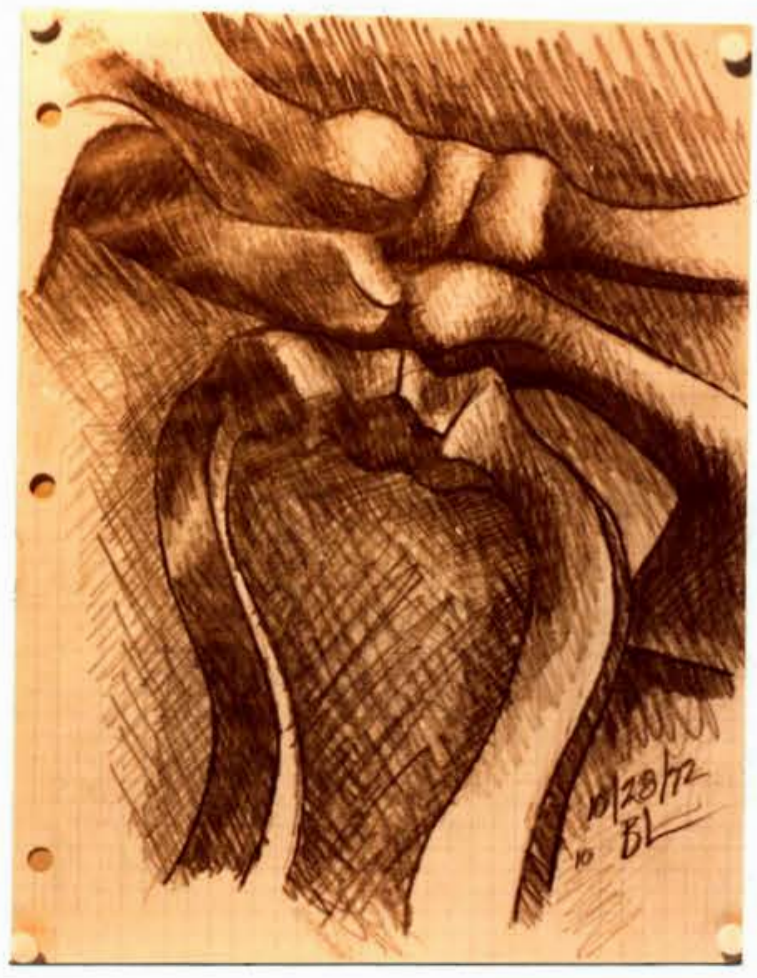

Figure 44. Drawing (10) $10 / 28 / 72$

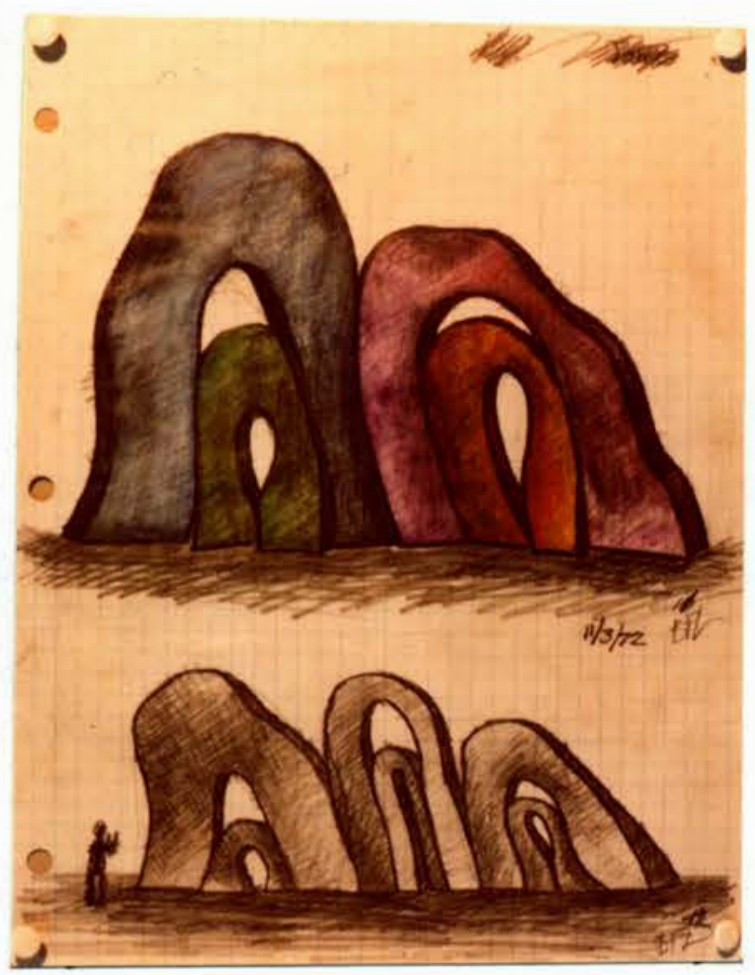

Figure 45. Drawing (11) $11 / 3 / 72$

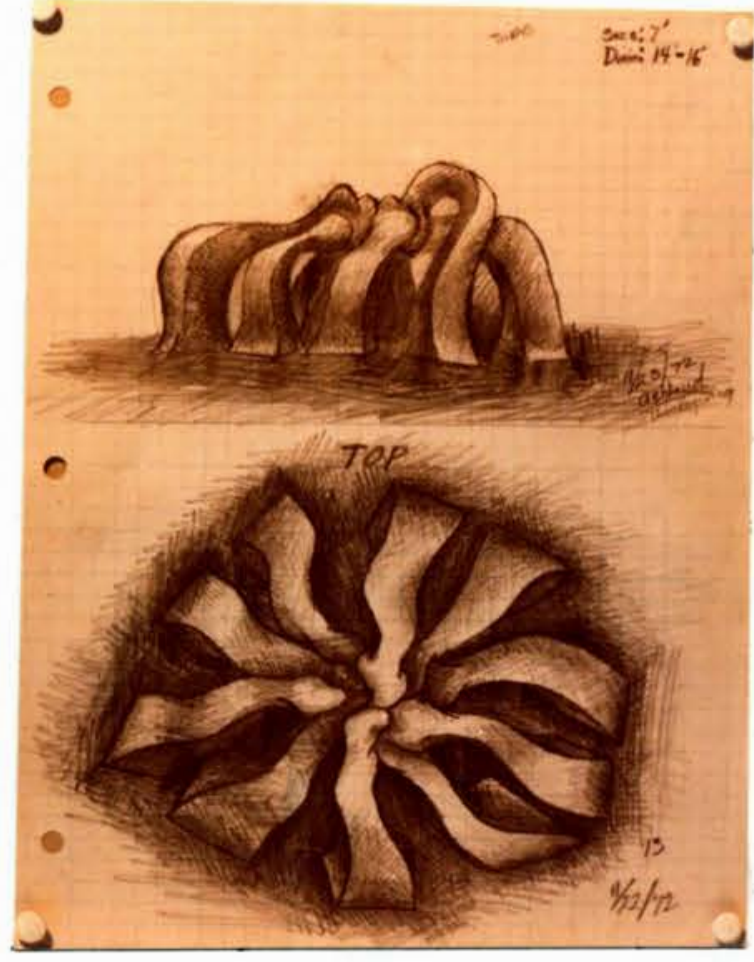

Figure 46. Drawing (12) $11 / 22 / 72$

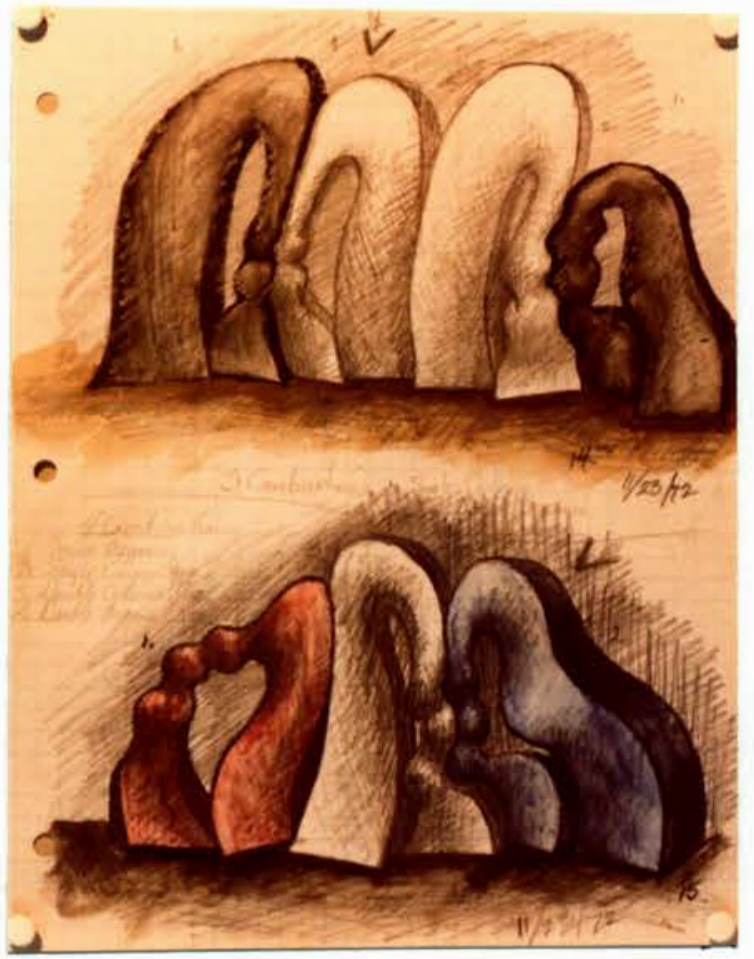

Figure 47. Drawing (13) $11 / 23 / 72$ 


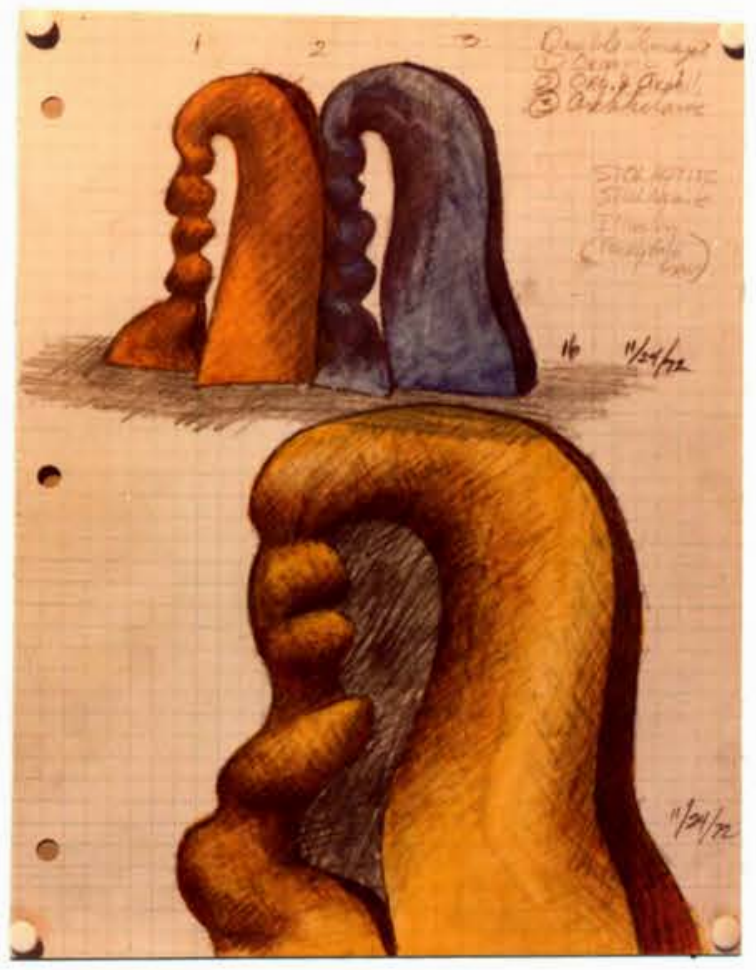

Figure 48. Drawing (14) $11 / 24 / 72$

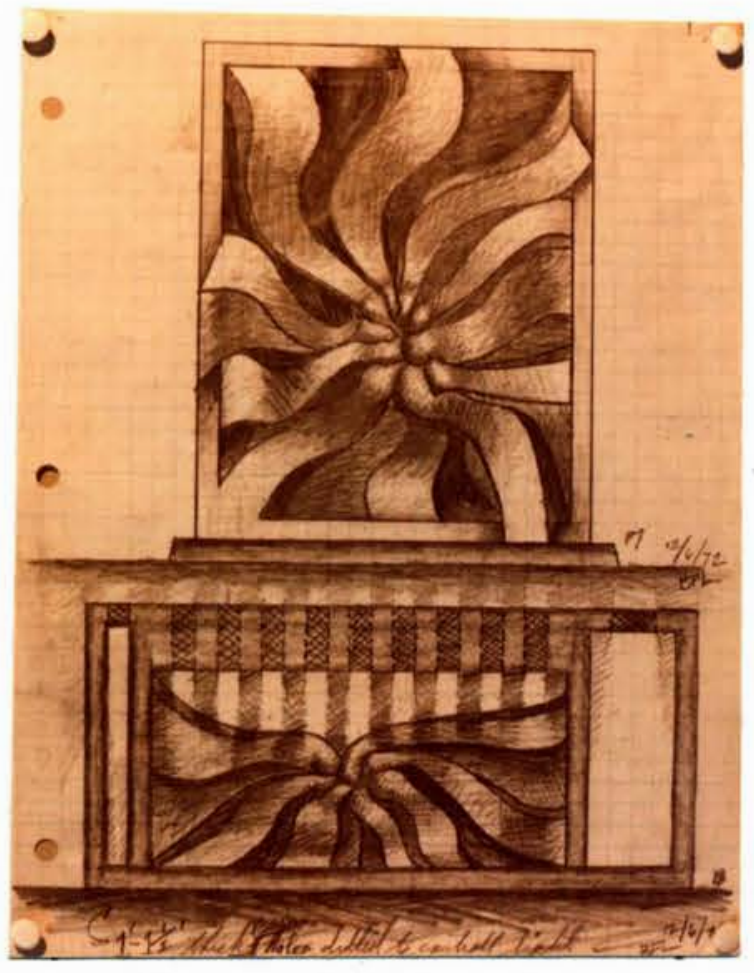

Figure 49. Drawing (15) $12 / 6 / 72$ 
SMASHED HAND PIECE (F1g. 50-51)

Composition

In my thesis group I was influenced by the contemporary style called "Super Realism" in sculpture. Rodin used the strong emotive power of the human figure. My thesis is based on developing the emotive potential of abstract form. I decided to use hand forms as the bimorphic-element. To abstract them I placed a large number of hands together in different positions (like a fish becoming an abstract element in a school of fish). The first impression would be of abstract forms, but only after much closer observation would the reality of the forms come through. To further abstract the hands, I used a torch which burned and altered the basic hand form. For the geometric elements I chose chromed steel rectangular blocks. The 1dea was that the viewer in looking closer at the biomorphic forms would, with his own reflection, become part of the sculpture. Thus the sculpture would be more personal in its impact.

\section{Material}

Polyester resin for flexibility in coloring, chromed steel for its mirror-like surface and its pristine characteristics.

\section{Critique}

The Initial idea of a chrome, mirror-like surface in reflection is successful. I did not foresee that its lack of definite surface placement would destroy the sense of weight which is essential to the sculpture. I think this absence of visual weight dissipates the fllusion of maimed and contorted flesh.

I do think both could be effective in a larger size with more 
surface area. Another alternative might be to have only the bottom rectangular steel block chromed and have the two rectangular forms (above the hand forms) in raw steel. 


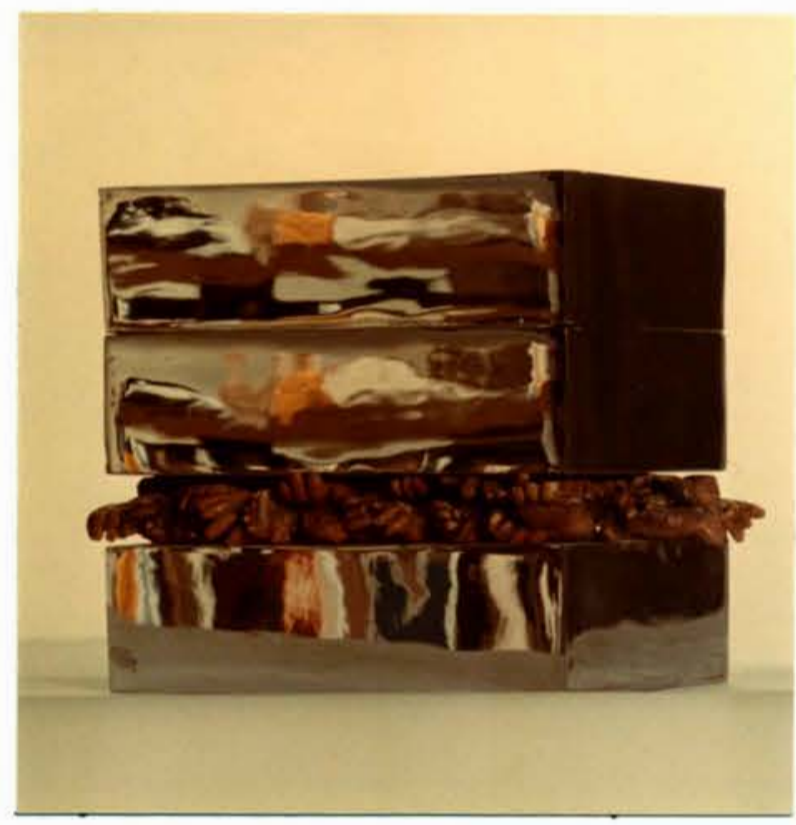

Figure 50. Smashed Hand Piece.

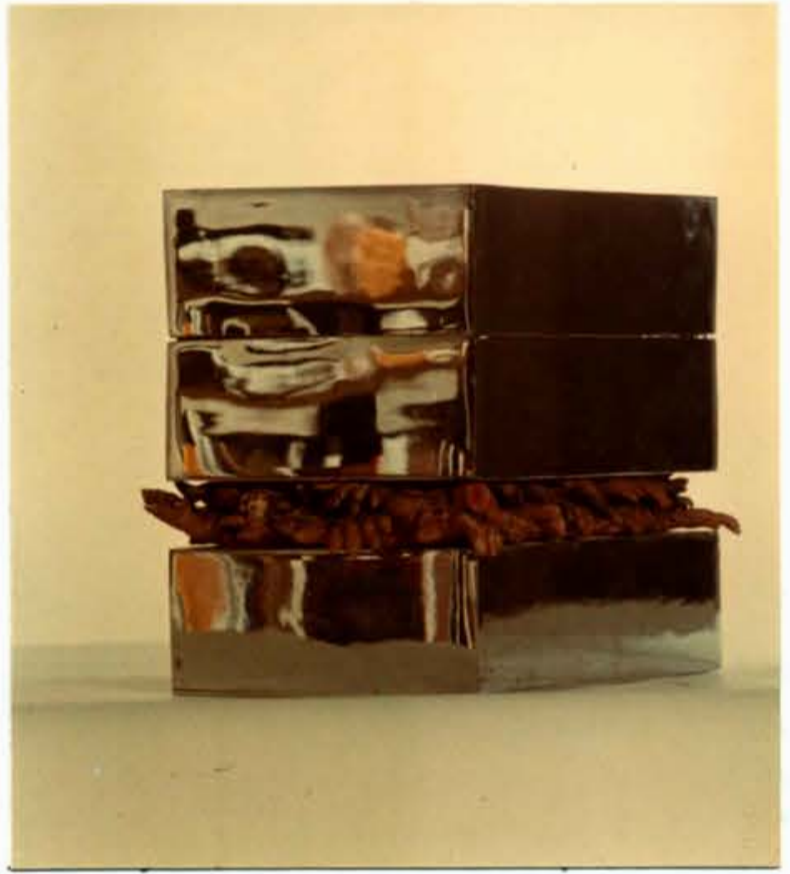

Figure 51. Smashed Hand Piece. Cast resin and chromed welded steel. Height 11". 
PEER-A-MID (Fig. 52-53)

\section{Composition}

In attempting to infuse more enveloping space as in the Harlequin piece, I thought of completely separating the organic and geometric elements. I decided to use another strong geometric form, the equilateral triangle, and to visually interweave two forms which would be similar in line, angle, division, and strength of direction. To balance the organic and geometric elements, I used sheet steel and bolted angle Iron, a very strong material easily linked with geometric images of strength. The organic forms were cast in a fresh-like color to project a warm, life-like quality.

\section{Material}

Polyester resin was chosen due to its flexibility in coloring. Steel was chosen because of its material presence.

\section{Critique}

To get the organic forms to hold one another together, I had to extend them to interlock among themselves. This interlocking destroys the geometric division of space and makes it more difficult to see associative lines. By accident, placing the two pyramids together, an equilateral triangle was formed in negative space. Thus, the name "Peer-a-mid" means, "Look at the shape in the middle." This negative space is dependent on the two positive forms which should reinforce the association between the two forms. Due to the surface orfentation, doubling the size of these forms would help the viewer realize the composition more easily. 


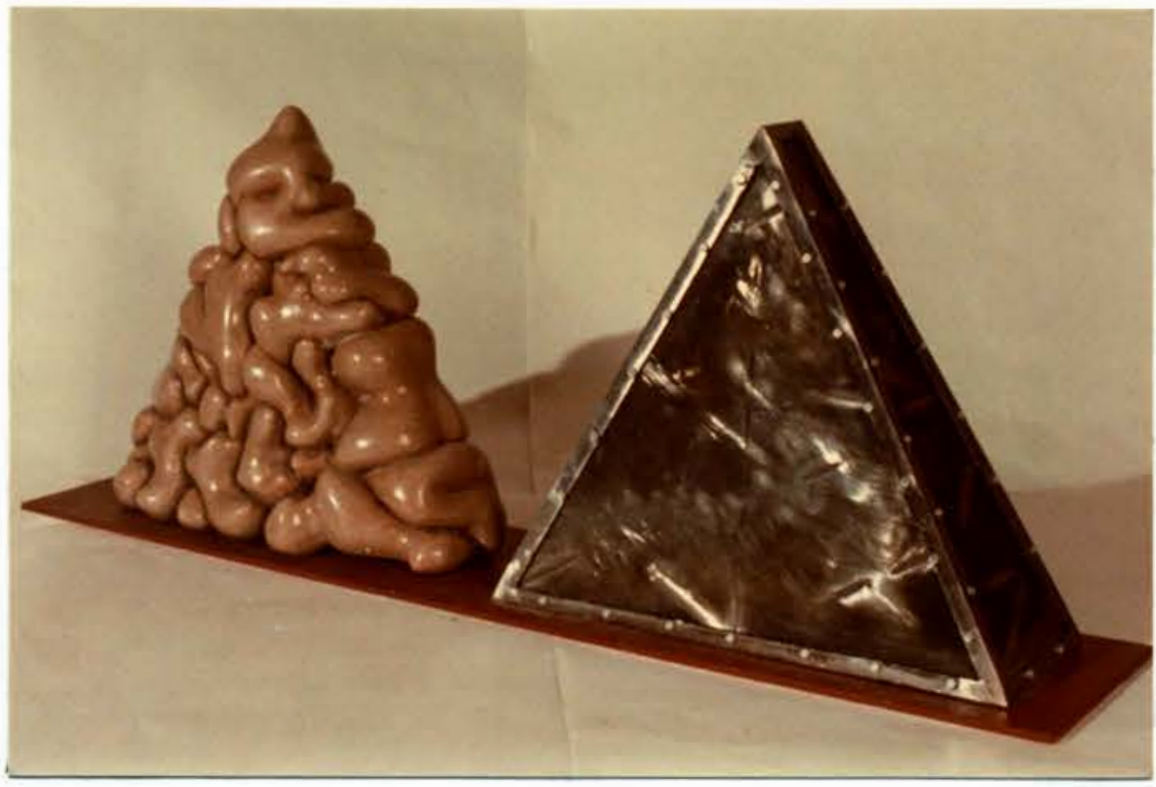

Figure 52. Peer-A-Mid.

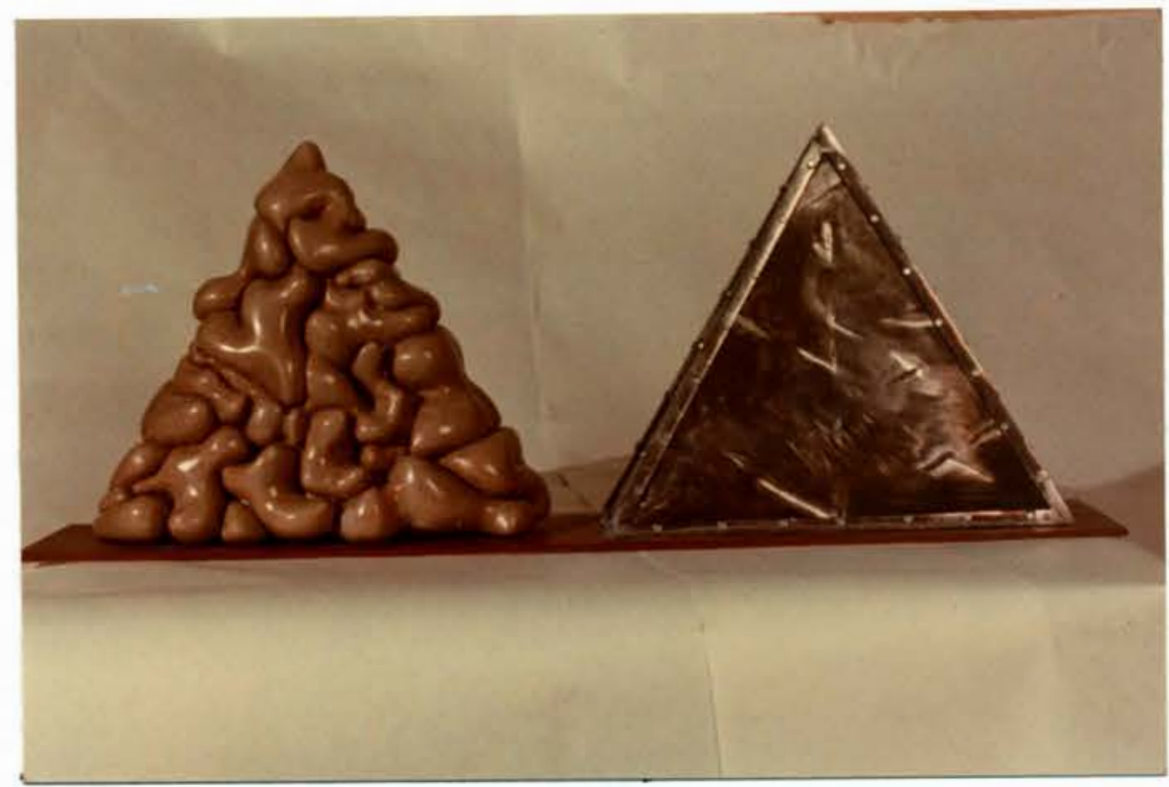

Figure 53. Peer-A-Mid. Cast resin and steel. Height 12 "'. 
OPPOSING PYRAMIDS (F1g. 54-55)

\section{Composition}

After finishing the Peer-a-m1d sculpture I decided to push the color possibilities. I decided to helghten the movement by dividing up the organic forms and thus doubling their number. Consequently I wanted to use a brighter and more active red-orange color for the pyramid form. Instead of side by side, the two triangles were placed directly facing each other. The idea was to create an environmental sculpture which would be a study for a much larger plece. The situation of the two pleces was partly derived from observing gable roof houses. With two opposite triangles I'm endeavoring to set up an impression of a roof with two invisible planes, extending from triangle edge to triangle edge. I used a fleshy tint to enhance the biomorph1c associations.

Material

Once again I used polyester resin for flexibility in coloring.

\section{Critique}

Part of the problem is to see this sculpture as a study. The larger composition would be seen by an individual standing between the two triangles. The assoctation of a form in one piece to a form in another is easier seen in the Peer-a-mid sculpture. I belleve color and form are well balanced in this sculpture. 


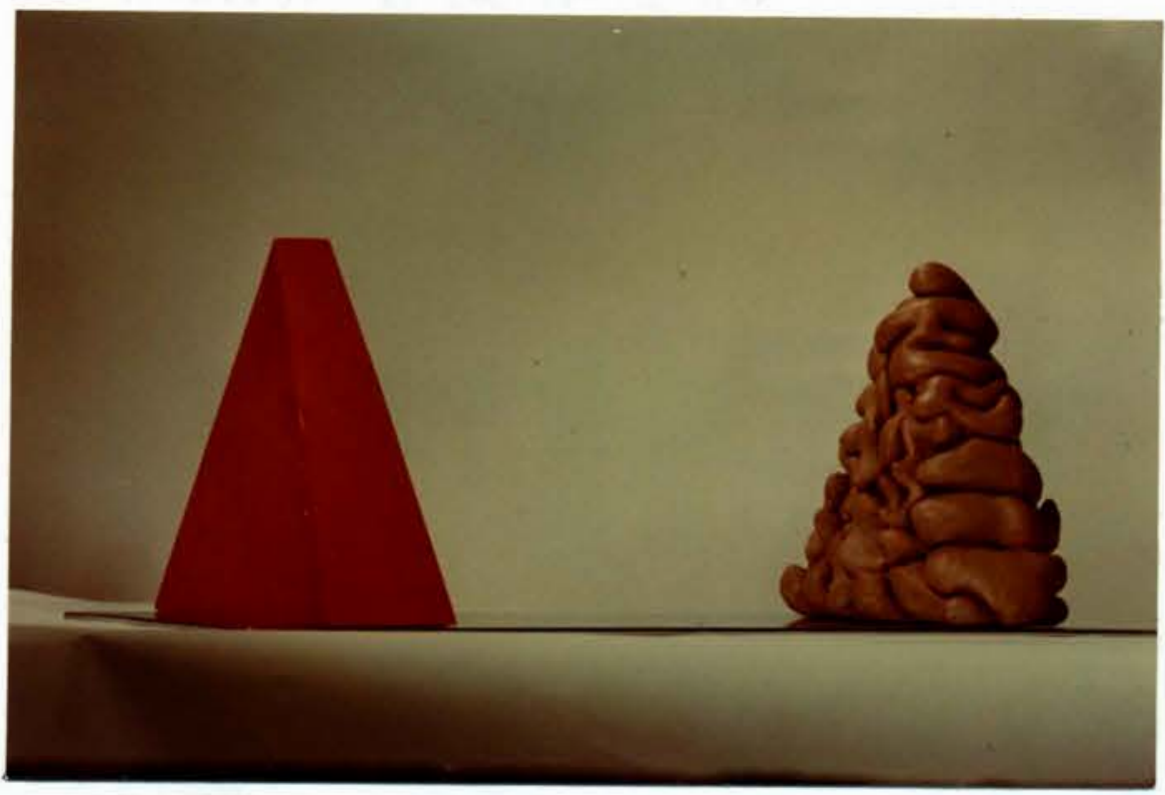

Figure 54. Opposing Pyramid.

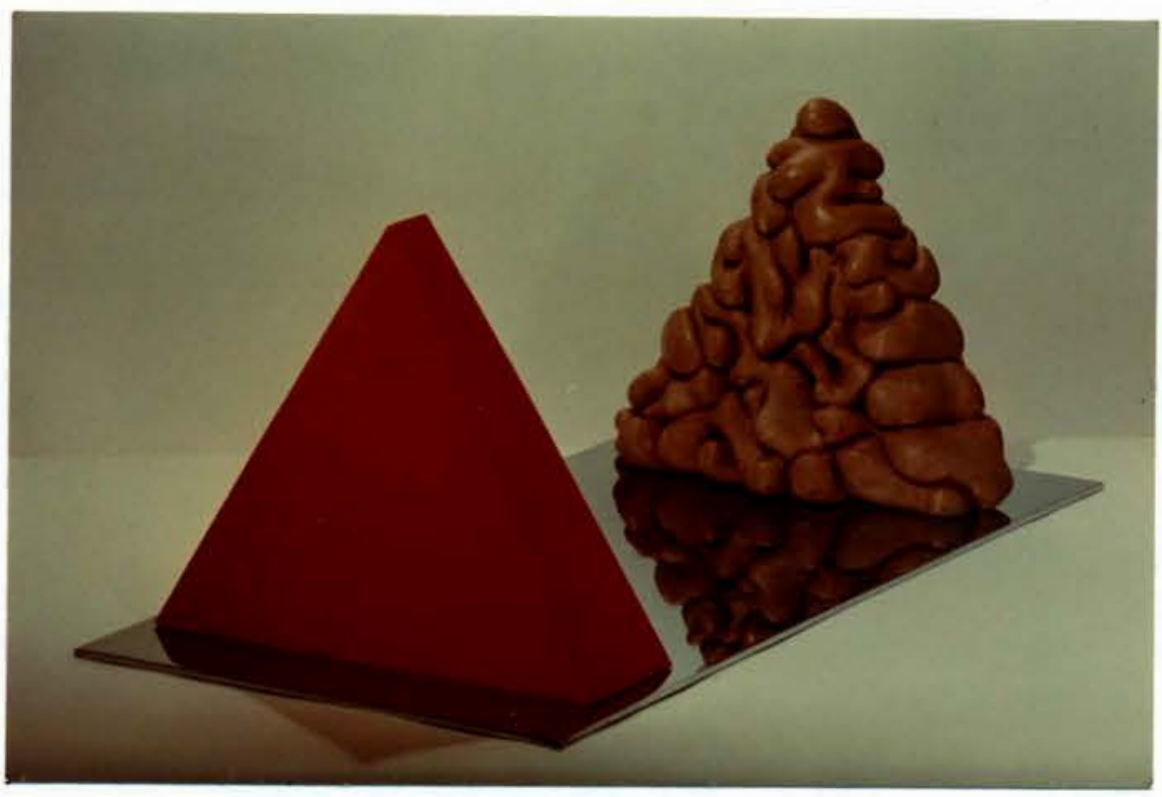

Figure 55. Opposing Pyramids. Cast resin and chromed steel. Helght $12^{\prime \prime}$. 
FACE CUBES (Fig. 56-57)

\section{Composition}

This is a vartation of the Body Cubes sculpture. Unlike the Body Cubes the face has more easily defined elements: eyes, nose, mouth. Due to the size, definition, and number of elements, there could be a larger number of individual pieces in the sculpture, thirteen in all. Earth colors strengthen the association to geologic cross-sections. I decided on graduated colors of green from light to dark. The color should help abstract the strong human facial impact and the whole unit.

\section{Material}

Polyester resin was used due to its flexibility in coloration.

\section{Critique}

I cannot see anything that I would want to change in this sculpture. Everything works as I wished. 


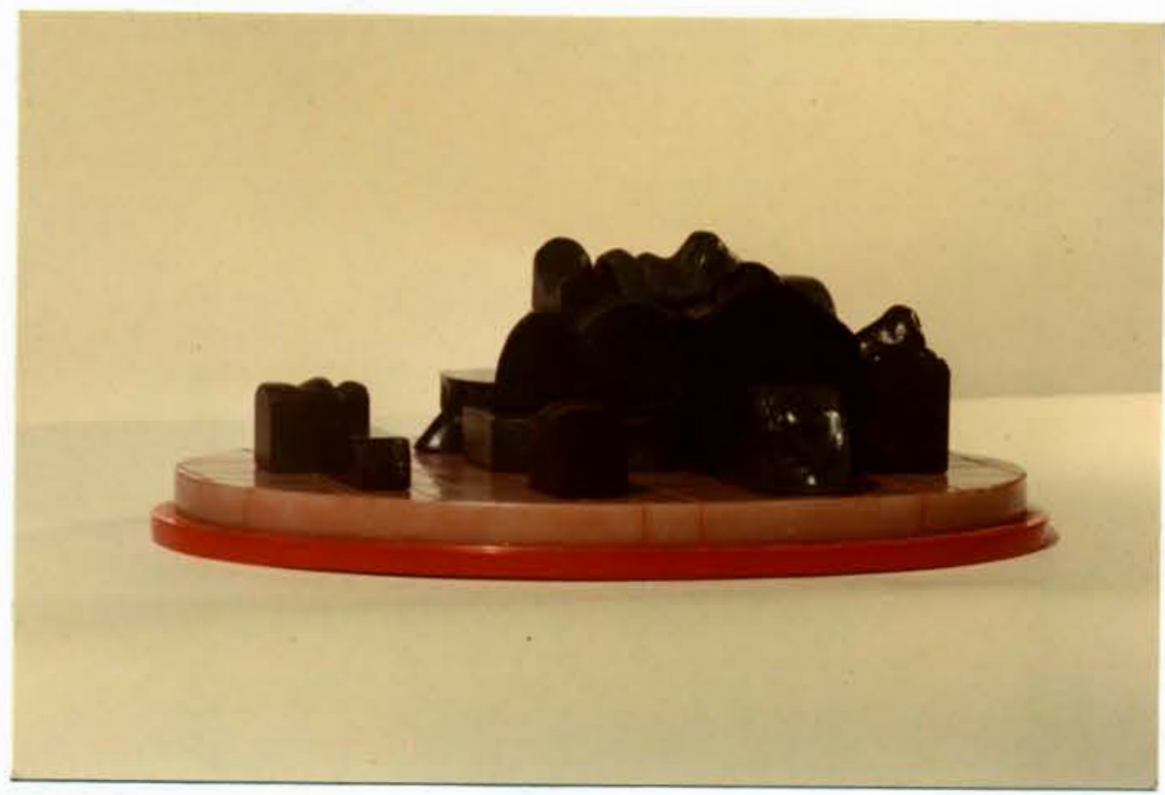

Figure 56. Face Cubes.

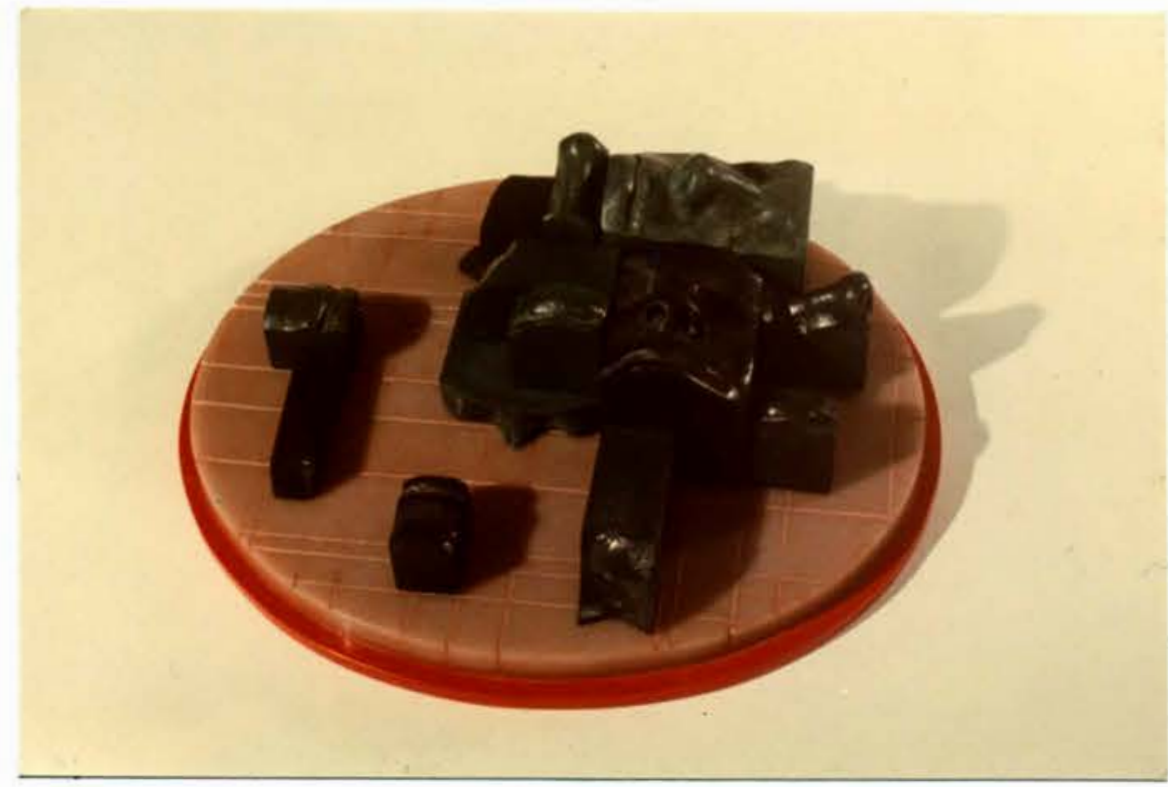

Figure 57. Face Cubes. Cast resin. Helght varies from 4" to 20 ". 


\section{BODY CUBES (FIg. 58-59)}

\section{Composition}

The Body Cubes was a reversal and, at the same time, a recombination of some previously used 1deas. From the Harlequin I took the Idea of biomorphic and geometric forms molded or blended into one unit. As In the Smashed Hand Plece I used the human form. But, instead of human forms being abstracted by large numbers of elements, the forms would be abstracted by cutting them out as if with a square-cornered cookie cutter. The resulting forms would be biomorphic with geometrized edges -- like geologic cross-sections of the body. From the two plece pyramid sculpture I took the idea of the complete separation of parts. The thought of children's play blocks had crossed my mind. Each individual piece would have five flat and hard edged sides and one biomorphic, human side. As far as ordered composition goes, the basic ratio of blomorphic form to geometric form is inherent in each piece. The individual pieces could be arranged and rearranged and be somewhat different each time. The form groups would always associate one to another. From the geological cross-section 1dea, I derived the basic earth colors. At first glance all the forms look to be black, but on closer inspection one is a blue-black, another is a red-black, another is a green-black, and only a few are pure black.

\section{Material}

Polyester resin was used due to its flexibility in coloring.

\section{Critique}

Due to its composition, certain arrangements will be stronger than 
others. All w1ll be sound in composition, but some will be more interesting than others. 


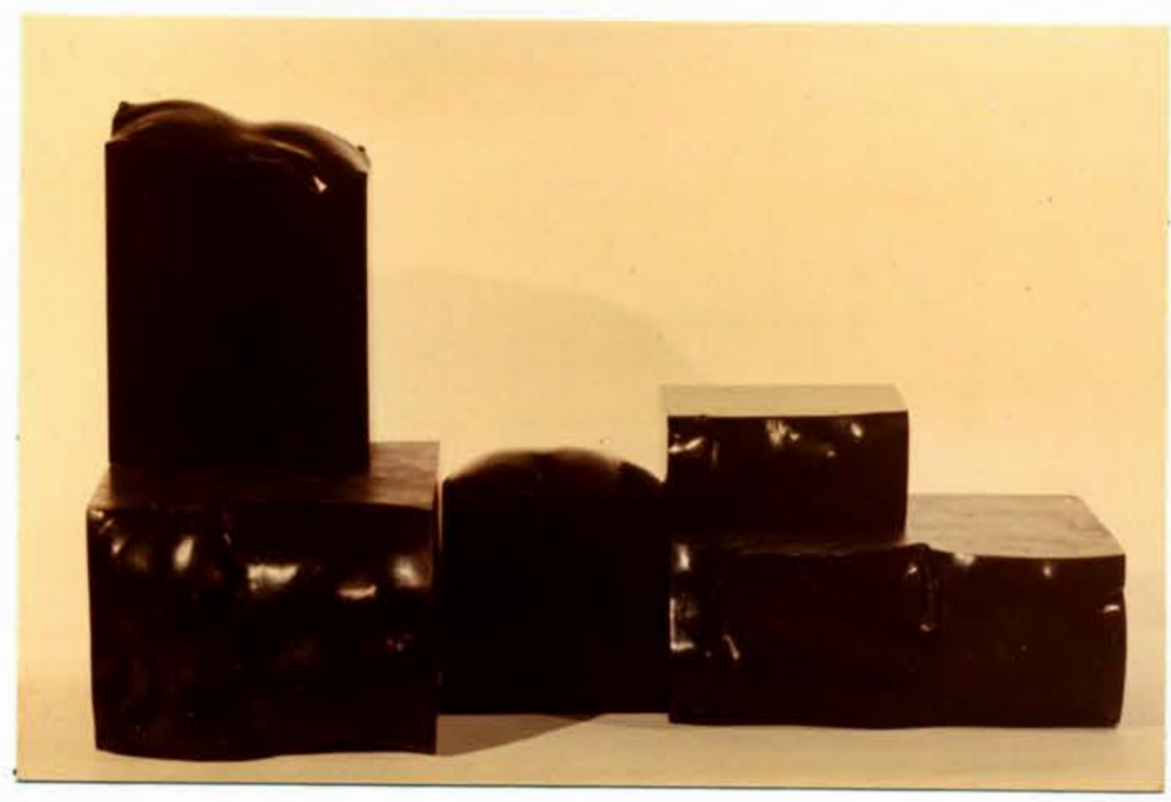

Figure 58. Body Cubes.

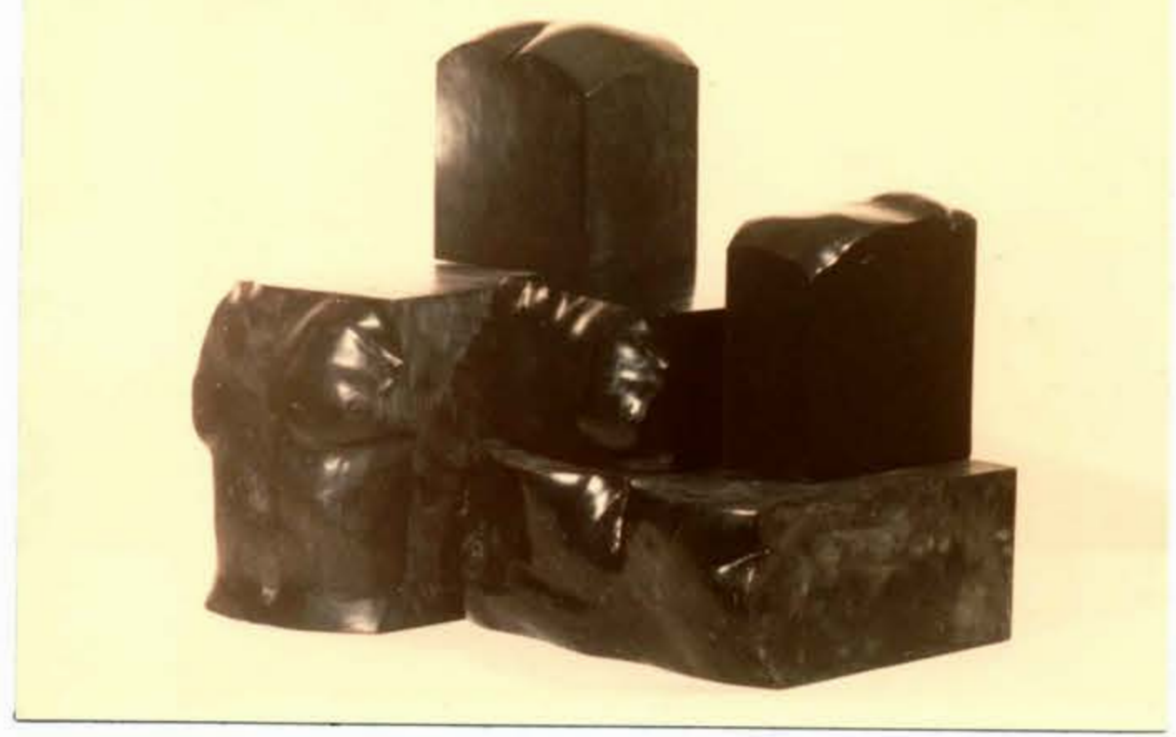

Figure 59. Body Cubes. Cast resin. Height varies from 6" to 72 ". 
Aqrawala, Vasudeva S. The Heritage of Indian Art. Bombay, 1964. Figure 2 .

Arnason, H. H. H1story of Modern Art. New York. Figure 9.

Hamlin, Talbot. Architecture Through the Ages. New York, 1953.

Figure 1 .

Luzzatto-B1l1tz, Oscar. Antique Jade. London, 1969. Figure 3.

Newman, Thelma R. Plastics as an Art Form. Philadelphia, 1969. Figure 7.

Read, Herbert. A Concise History of Modern Sculpture. New York, 1974. Figures $5,8,10,11,12,13$.

Rose, Barbara. American Art Since 1900. New York, 1975. Figure 6.

Slebert, Erna and Werner Forman. North American Indian Art. London, 1967. Figure 4. 